\title{
Coding for the Brain: RNA, its Photons, and Piagetian Higher-Intelligence through Action
}

by

Robert R. Traill (ORCID: 000-0001-8089-9412)

29 Charlotte Street, Blackburn South, 3130, Victoria, Australia — rrtraill4@gmail.com

Philosophy Dept. (HPS), Melbourne University

\begin{abstract}
Modelling human intelligence? Hyland identified three approaches: $\bullet$ Physiological, $\bullet$ Mentalistic (as if outside 3D space), and $\bullet$ Mechanistic. Arguably their apparent incompatibility arises from a mistaken choice of scale, centred on the synapse as a basic unit for thought. Instead RNA-codons are now proposed as those fundamental elements (cf. Hydén's forgotten 1960s findings). This conclusion also seems compatible with both (i) information-technology's digitisation, and (ii) Piaget's concepts of "schèmes," and developmental stages.

For the more-complex code-structures ("schémata") needed for higher Piagetian stages, their necessary physical configuration is then considered — packable into virus-like "boxes" (capsids - typically 125nm diameter).

These could be free to relocate into cortex-"archives" either within Rakic's migratory new-neurons, or the bloodstream!

Such ultra-miniaturisation would need to communicate by INFRA-RED signals - via myelin coaxial cables, but also somewhat free to operate radio-like, dependent on "call-sign" coding like phone-numbers. (Sun's team demonstrated such electromagnetic duplicate nervetransmission, in 2010). Also any "radio-like" abilities would allow continued participation after relocation (as if mobile-phones using WiFi).

Meanwhile traditional synaptic Action-Potential signalling is seen as analogue adjustment-signals: (i) in orthodox peripheral muscle-control; (ii) as constantly updating deep-brain "wiring” via well-known Hebbian principles (an important, but secondary task — after main infra-red transmissions); and (iii) recognized orthodox analogue-mechanisms like local navigation.

Gut-contents have a surprise-role in mental abilities a phenomenon which is also tentatively explained as a supplementary "useful-junk RNA" source.

Piaget-as-Epistemologist saw "equilibration" (coherence) as the vital-but-fallible criterion for theory evaluation, both in the brain, and within science.

That philosophy is applied here.
\end{abstract}

\section{Keywords:}

- Mental pathologies - a new model

- Gut microbiome aids intelligence (how \& why)

- RNA \& optics (not synapses) as vertebrate brain encoding

- Memory-migration to cortex (in $125 \mathrm{~nm}$ capsids \&/or in neurons)

- infra-red WiFi \& RNA-coding as key to brain malleability

- Scientific Method since Popper

\section{CONTENTS}

(Revised version, June 2022)

First issued: 6 June 2020.

28 June 2020: re-write of $\S 4.4-\S 4.5 .2$

12 July 2020: 'Conclusion' added.

23 Dec 2020: Minor changes (90\% gray 26,26,26). 4 June 2022: major updates (very-dark green 0,25,0), mainly in Parts B \& C.

\section{PART A - MECHANISMS TO GET HIGHER INTELLIGENCE 2}

1. INTRODUCTION: 2

1.1 Modelling Human Intelligence? 2

1.2 Critique of Hyland's Three Approaches 2

1.3 Reconciling these three approaches 3

2. TACTICS FOR THIS REVERSE-ENGINEERING 3 2.1 Option 1: Start from InfoTech Principles 3 2.2 Option 2: Piaget's Mental-Mechanisms 4

3. PREVIEW OF THE FINDINGS 4

3.1 On Theory and its Role 4

3.2 "Pre-written Coding-Strings" 4

3.3 Signals between those "on-tape"-sites 5

3.4 Redundancy 5

3.5 What "writes" the RNA-memory-coding? 5

3.6 Address-Codes and How used? 6

3.7 Relocating a "written" memory undamaged? 6

3.8 Moving Memory to the remote Cortex 7

3.9 Gut Microbiome affecting the Brain 7

4. The SAME Topics In MORE Detail 7

4.1 Theory, Empiricism, or Both-if-feasible? 7

4.2 RNA-coding needed for Advanced Intellect - Figure (i) 9

4.3 Signals between RNA-sites 9

- Figures (ii) and (iii) 10

4.4 Need for Managed Redundant Coding 11

4.5 Address, Message, and Structure Links 12

4.5.1 How to Find and "Talk to" Distant Sites? 12

4.5.2 Augmenting Chemical-Links within a Schéma 12

4.5.3 Beyond Chemical-Links 12

PART B - RELOCATING THE NEW INTELLIGENCE CODING 13

5. STORING CODE TO LTM IN THE CORTEX 13

5.1 New Memory-Records do Re-locate 13

5.2 Rakic's Neuron-Migration to the Cortex 13

5.3 Schéma to the Cortex - perhaps as a mere "Telephone Message"? 14

5.4 Feasible "Mail-Services" to the Cortex? 15

5.4.1 Case (a) - inside Rakic's new migrating neurons 15

5.4.2 Cases $(e \& h)-$ Axon transport of solid cargo 15

5.4.3 Pros \& Cons of such Transport by Glia-or-Axons 16

5.4.4 Case $(f)$ - Capsids via the Bloodstream! 16

- Figure (iv) -16

5.5 Mixed routes for Schemoids into the Cortex? 17

5.6 An Enhanced Respect for the Axon? 18

\section{PART C-APPLICATION: SEEKING TO EXPLAIN GUT-INFLUENCE ON INTELLIGENCE 18}

6. GUT AND ITS SURPRISES 18

6.1 Intelligence etc. suffers if gut is Germ-Free! 18

6.2 Existing Part-Explanations for "Gut-Brain" 18

6.3 How could gut-diversity raise intelligence? 19

6.4 How could such pre-coding reach the hippocampus? 19

7. IN CONCLUSION 20

REFERENCES 20

END 24

Also available in German: (Traill, 2022) 
Part A -

\section{Mechanisms to get Higher Intelligence}

\section{Introduction:}

This topic covers some unfamiliar interdisciplinary concepts, so it may be helpful to start with the simplified PowerPoint account (Traill, 2012): www.ondwelle.com/MolecularScheme.ppt-;

\subsection{Modelling Human Intelligence?}

It has long seemed impossible to explain human intelligence physiologically. Don Bannister (1968) argued that doubt 50+ years ago, and more recent voices have tended to agree: e.g. Fuster \& Bressler (2012), Gallistel \& Balsam (2014), Koch \& Marcus (2014), Trettenbrein (2016), Horgan (2016), Brette (2017) - and, more vehemently, Rose (2015).

Hyland (1981: p46-47) concedes that physiology does at least agree on a $3 D$ existence-in-space, with a scale of observability for the relevant hypothetical entities and their behaviour. He does not directly take the matter further, but he does also identify two extra alternatives, yielding a debatable trilemma with these two extra domains:

(Ibid. p48-50): Mentalistic hypothetical constructs as "thoughts [which] exist not as objects in the physical world but as private experiences which can be described..." (and that includes unconscious thoughts). These experiences he deems as not existing in 3D-space, but without offering any new ideas for explaining such entities further - thus leaving them abstract. - And some might say that this dodges the main issue.

(Ibid. p50-54): Mechanistic hypothetical constructs as analogies (such as Freud's "energy", or as calculator, or on/off switches - offering structure whereas physiology is seen as offering function). Hyland quotes Broadbent's view of such transitioning-concepts as diagrammatic “"boxes' joined by 'arrows"” — with detail presumably omitted (as is common in schematic organisational diagrams); and again we might see this as issuedodging if no detailed description is offered for submechanisms.

Quoting Fodors's (1975) opposition to reductionism in psychology, Hyland (1981) asserts that: "[Orthodox] Physiology does not describe the parts of psychology [mechanistically] and so psychology cannot be microanalysed by physiology.",

- To which one might suggest:-

"Perhaps it is now high time that orthodox physiology be augmented by a discipline which can offer plausible $3 \mathrm{D}$ explanations for psychology and its mentalistic concepts?"

\subsection{Critique of Hyland's Three Approaches}

The apparent incompatibility of the above three models is arguably caused by our view being too macro in each case. - After all, e.g., infectious diseases were but poorly understood until the discovery of viruses, which are much smaller (and hence less observable) than bacteria. Thus:

NEUROPHYSIOLOGY is unwittingly fixated on the supposedly-basic synapse. Certainly the synapse is important, but is it really the most fundamental unit for advanced intelligence? Since Ramón-yCajal and Sherrington discovered it in the 1890s, noone seems to have offered a clear account of how synapses could encode advanced vertebrate abilities - i.e. anything more than the simple behaviourist repertoires of sea slugs (Squire \& Kandel, 1999, Chs.4-6), or B.F.Skinner's restricted environments.

MECHANISTIC (here including ELECTRICAL).

"Mechanism, in philosophy, ... holds that natural phenomena can and should be explained by reference to matter [inanimate-in-itself] and motion and their laws" ...[hence needing] "the mathematical method." (Encyclopaedia Britannica - with insertions; accessed online 11 May 2020 - my italics).

That definition presents no great problems for happenings in our everyday macro-world - but if we leave it there, it hardly fits the macro-biological world we experience. Hence Hyland's misgivings.

We get much closer by looking at cells, axons and synapses through the microscope, and closer still using the electron-microscope and biochemical findings. But even then, such ensembles as we know them, do not seem yet to offer a coherent explanation of how advanced intelligence might be possible. One could go further into the oftenunobservable ultra-micro, as we shall see; but that is deeper than Hyland's analysis takes us.

(Meanwhile, regarding the above definitional reference to mathematics:- In Piagetian terms, that should be interpreted as including such arcane specialties as "set theory, group theory, and

\footnotetext{
${ }^{1}$ Italics and [...]'s are mine. (Reductionism is also discussed in Traill (2015b); and in the 2007 preface-and footnote-D of Traill (1976/2007)).
} 
topology - e.g. Piaget (1949); Beth \& Piaget $(1961 / 66)$.)

MENTALISTIC constructs or "thoughts" are clearly not scale-dependent. They can be as large, or as small, or as fantastic as we choose. However it will be obvious to psychologists that we will easily be biased into modelling those features of reality which are the most salient (usually the most macro), and these are not necessarily the most influential causally. So if we are seriously seeking hidden basic causes, we may have to be inventive - especially if we don't really know in advance what to look for. (Nevertheless that inventiveness should usually be constrained by what is already known about the basic laws of physics and other relevant disciplines).

\subsection{Reconciling these three approaches}

Hyland (1981) saw no prospect of that unity, but let us consider these ideas based on scale-change: (a) If we shift our attention on mechanistic structure down to a suitable molecular level, then we may find more suitable alternative-ways of encoding advanced mentalistic activity. And

(b) such molecular levels might also offer new micro-perspectives for physiology, and hence these might suggest helpful extra coding-alternatives beyond the synapses and action-potentials.

The main problem here is that such processes must almost certainly be beyond direct observability, at least initially — so one is left to do interdisciplinary DETECTIVE WORK: (i) collecting and evaluating existing indirect evidence (revised occasionally), (ii) assess the remaining approaches; and then for each: (iii) seek (at least conceptually) to build up a plausible model by "reverse engineering", as if one were designing the original system oneself (but now with the useful knowledge that the real system does actually work, so one is not just chasing rainbows).

Central to that collective approach is the art-andscience of EPISTEMOLOGY - (Knowledge Theory) seeking to understand what knowledge is; plus how it is or-can-be: stored, interpreted, transmitted, and retrieved - preferably using general principles, not too dependent on the particular physical coding-medium.

Note that one hard-won finding for all types of knowledge-theory is this: The default strategy for gaining new knowledge is simply Trial-and-Error pre-guessing the true-answer (usually amongst many failures), then seeing if it works in actual practice (\&/or "equilibrates" conceptually when we seek to assimilate it into any pre-existing knowledge). I.e. this basic defaultlearning is not the noting-down of lessons-orobservations as is usually assumed. (Of course some such noting-down can occur, but that requires a prior acquisition of suitable intelligence - not available at first, and indeed the subject of inquiry for this very project).

\section{Tactics for this Reverse- Engineering}

Here are two alternative suggestions about how the current intelligence-explanation investigation could have been started. (As it turned out, the second alternative was the one adopted in this project):

\subsection{Option 1: Start from InfoTech Principles}

We could start by assessing that even moderately advanced intelligence could only be achieved via some sort of digital coding - and that the traditional Action-Potential (AP) synaptic system has never shown any reliable sign of such digitisation. That dilemma forces us to postulate an extra-but-digitisable system (elsewhere named the "[R]-system"). Never mind if we cannot yet imagine how such coding could be embodied physically, though we can probably guess that it will be ultra-micro.

Secondly we might note that (unlike normal computers) any natural brain has the extra role of managing its own growth-and-maintenance. Hence it must have some sort of mechanism for that purpose, though this mechanism need not necessarily be digital. In fact wherever "volume control" is needed, it could be an actual advantage to use nondigital "analogue" signals - especially as that's what is needed for the well-known neuro-control of muscles. Which leads us back to familiar territory:-

Biologists are already well-aware of the "Action-potential \& Synapse" system; (recently named "[A]"). And we can by now see that this is effectively an analogue system (no-matter how switch-like it appeared to be in the 1960s!). Thus it would suit the above-mentioned role of analoguecontrol for growth-and-maintenance (along with its obvious control of muscles). Note that this is consistent with Hebb's (1949) notion that synaptic connections become reinforced according to their usage (i.e. maintenance - which would have to be after key messages had passed through, presumably as "[R]" traffic!). Conversely non-use would lead to non-maintenance - effectively a case of the wellknown "Wallerian degeneration."

That seems to leave our not-yet-identified (but expected) digital "[R]" system as the controller of 
advanced thought - thereby relieving "[A]" of that responsibility; - and thereby freeing us from the long-standing wearisome task of trying to force [A] into that role!

In seeking digital-coding possibilities at molecular level, we are quickly led to suspect DNA \&/or RNA, and we shall come back to them later, after they have been spotlighted again within Option 2:-

\subsection{Option 2: Piaget's Mental- Mechanisms}

Partly borrowing from Kant (1787: ed.2), Piaget (1896-1980) looked at the problem from the viewpoint of Epistemologist-Psychologist and Developmental-Biologist. - His treatment was essentially Mentalist, with no significant reference to synapses at all, but he did achieve some pseudomechanistic accounts amongst his abstract entities - arguably enough for later interpretation in real physical terms, as attempted in the current project.

His main theoretical innovations were (i) his well-known four ${ }^{2}$ developmental stages, which can be construed as • a base-level ("sensorimotor," here also called " $\mathrm{M}^{0} \mathrm{~L}$ ") plus a hierarchy of -three meta-levels $\left(\mathrm{M}^{1} \mathrm{~L}, \mathrm{M}^{2} \mathrm{~L}, \& \mathrm{M}^{3} \mathrm{~L}\right)$ - the four together comparable to Kant's two levels: Basic and "Transcendental").

But more immediately relevant here:-

(ii) The concept of the "schème" as an element of ACTION (\&/or its encoding, though he was less clear about that). [Also see Preston et al (2013; Box 1), Traill (2008, Appendix p.21)]. Note its verb-like quality (as if using a simple linear recipe of movements) - not a noun-like direct representation of some sub-object.

Through trial-and-error experience, such schèmes could then be suitably linked into $\mathrm{a}$ collective "schéma" - which might then (e.g.) offer the noun-like concept of a dog-or-table, or whatever; - like drawing a sketch (which is what schéma literally means). And note its similarity to the notion

\footnotetext{
${ }^{2}$ There is active re-evaluation amongst neo-Piagetians such as Commons et al. (2008) as to how many distinct levels should be recognised; but the present discussion applies in principle, whatever the number. - Here this is taken to be four levels, as in Piaget's original accounts.

Meanwhile note that similar concepts are now evolving independently within neuroscience - invoking the notion of "top-down control", and attributing "hierarchical top-ness " $\left[\mathrm{M}^{\text {top }} \mathrm{L}\right.$ ?] to the more anterior part of the frontal cortex: (Badre et al, 2010; Jayachandran et al, 2019; and Malik et al, 2021).
}

of "motif" as used in computer neuro-modelling, Sporns \& Kötter (2004).

But what physical entity could embody the encoded basic 1D schème (as if written down)? For such a static stored form, RNA and DNA are obviously worth considering - which takes us to the same conclusion as with Option 1 above.

In fact this same duplicate RNA-conclusion seems closely analogous to the mental "motif" attributed to parts of mRNA, (Sahoo et al, 2018).

Meanwhile dynamic speech-like "read-outs" of such static-text coding raise new problems, and we will come to those later, in $\S 3.3$ and $\S 4.3$ ).

\section{Preview of the Findings}

It may be helpful at this stage to preview (here in §3) where the argument is leading - mainly summarising a previous account (Traill, 2019). I will extend the topic in more detail in $\$ 4$ - and then investigate related developments in Parts B and C.

\subsection{On Theory and its Role}

It is assumed here that a theoretical approach is legitimate, especially if it takes serious pains to be interdisciplinary, coherence-seeking, and responsive to unexpected evidence (empirical or neo-theoretical). That may mean departing from Popperian advice, but in a way which makes sense within Cognitive Psychology and current Philosophy.

Popper had partly followed Mach and Carnap etc. in seeking fully-rigorous foundations in scientific development (so induction, analogy and coherence were discredited as merely suggestive). Unfortunately, because of their unconscious assumptions about supposedly infallible perception (thus bypassing the arcane problems of Humean scepticism about rigour (1777)), they did not see that this worthy aim was actually impossible, and that their perfectionism was sometimes a serious obstacle to progress. See Quine (1951) and Creath (1991).

\section{2 "Pre-written Coding-Strings"}

The "written-down" coding-medium for the missing [R] system is indeed postulated to be part of the RNA strings of digitised sites transcribed from inherited DNA. ${ }^{3}$

\footnotetext{
${ }^{3}$ Until 2001, such transcribed RNA was assumed to be mostly "messenger-RNA" (ㅍNA), dedicated as coding for proteinmanufacture (plus special rRNA or tRNA), while the rest was seen as useless junk: ncRNA ("non-coding"). However Mattick $(2001,03,04)$ indicated that, for humans, about $\mathbf{9 7 \%}(!)$ of the RNA was ncRNA and hence available for other tasks. - Thus the role of "regulators" was soon claimed for some of this ncRNA. But that still leaves scope for yet further tasks, and this present project postulates that most of these are inherited action-RNAs. (Note their verb-
} 
Such "action-RNA" would thus be pre-coded with "default text" deemed to have varying degrees of usefulness-for-action in this initial form.

Some action-RNAs of this copious supply are seen as collectively carrying inherited species-wisdom including "intuition" and vital reflex actions, like breathing, sucking, or in some non-humans: walking.

The rest are seen as many "blank prototypes" loosely encoded as potentially useful sequences, and subject to mutation \&/or selection (like oddments in a handyman's workshop) - all to avoid any difficult-to-achieve "writing-down" or "tape-recording" process. ${ }^{4}$ After trialuse, their many "failures" would be re-cycled — a micro version of "Darwinian" Trial-\&-Error - with more selection following later for attempts at coherent schémaassembly for the next-higher Piagetian stage.

( $\$ 5$ below contemplates the possible existence of a further type of action-RNA - more unruly, and coming from a different source.)

Successful encodings might then perhaps ultimately transfer into more stable DNA (in the cerebral cortex) for Long Term Memory (LTM) - OR they may be stabilised by then in some other way, e.g. by capsid-enclosures protecting them from enzymes; (see $\$ 3.7$ below).

\subsection{Signals between those "on-tape"-sites}

For several reasons (see $\S 4.3$, page 9 below), the alternative $[\mathrm{R}]$-type signalling-methods needed here are seen as optical photons: - usually as being near infrared "NIR" (or "IR" to be more general): with probable wavelengths of about 0.8 to $4 \mu \mathrm{m}$. These are seen as able to use myelinated nerve fibres as ultra-micro coaxial cables - so such fibres would now have a dual role!). However the NIR signals should sometimes be able to travel shortish distances free from the cables altogether (like radio, if the optical conditions are right ${ }^{5}$ ), unlike the [A] signals.

like role, whereas mRNA is noun-like, while "regulators" would be adjective/adverb-like).

${ }^{4}$ Such Lamarckian writing-or-recording is not impossible, but it requires specialised "equipment" which is unlikely to occur at such basic (sensori-motor) levels, especially as it also needs maintenance as explained in $\$ 3.5$ below.

Such problems can be solved by adequate "intelligence" (the theme of this paper), but that is not to be expected at the elementary beginnings of a self-organising learning system.

${ }^{5}$ Needed optical conditions obviously include sufficient transparency (for the frequencies involved), but less obvious is the important need to cope with irregular-and-mobile terrain. That was a technical obstacle hindering the internet and mobile phones until the patenting of the WiFi system for reconciling two-or-more simultaneous beams (likely to bounce off different surfaces, etc.) - (O’Sullivan et al., 1996), based on astronomical redundant-interferometry (Hamaker et al., 1977).

\subsection{Redundancy}

Redundancy is seen as essential to avoid dangerous rogue or inadvertent "button-pressing" — and that is here seen as avoided by requiring a "quorum" among a "choir" or "committee" of near-clones. At the intermolecular level, that should not be too difficult to achieve; but it would be well-nigh impossible for the neural circuits which are often attributed to [A]-based models. ${ }^{6}$ - One key benefit from ultra-miniaturisation.

Anyhow, such near-clone action-encoding elements (presumably RNA) can conveniently be named "tatons"16 and their "choirs-or-committees" are seen as physical embodiments of Piaget's "schèmes". Details below.

\subsection{What "writes" the RNA-memory- coding?}

How does relevant "learned" encoding come to be stored on such tatons? One obvious-but-dubious suggestion is that the message is SOMEHOW "transcribed" onto the RNA as a result of experience (as if by tape-recorder). As mentioned in $\$ 3.2,{ }^{4}$ this Lamarckian concept is not automatically false, but it would require fairly sophisticated mechanisms and their maintenance plus their long-term evolution (or their design, and that requires pre-existing intelligence which makes the argument somewhat circular if we are trying to explain such intelligence). So if we cannot explain this recording mechanism in some bio-feasible detail, at least in principle, then we should seek some better explanation.

An attractive alternative was actually offered long ago by Kant (1787) who admitted to "turning the idea on its head" thus: If reality cannot be copied meaningfully into our mental-model, then maybe multiple guesses by our own mentality can be checked back against that reality! That gives us the "back-to-front" trial-\&-error procedure, which Piaget later developed but without much public-directed explanation ${ }^{8}$ (indeed so little

\footnotetext{
${ }^{6}$ The [A]-system's synaptic firing itself does also need a different sort of quorum of AP-inputs for each neuron triggered, but such activity is still mainly analogue (and arguably focussed on maintenance rather than thoughtcoding) - so it seems inapplicable here anyhow.

Also note that the traditional neural circuit recording [A] may still suit analogue situations such as local-navigation (Nadasdy et al. 2022), or perhaps even analogical thought. But our present concern is with concepts which are necessarily digital.

${ }^{7}$ Of course Darwin and Wallace re-invented this process to explain species-evolution. Next Jerne (1955) re-invented it again to explain immunological mechanisms - then offering it as a general epistemological principle on how knowledge can seed itself even in unlikely conditions.

${ }^{8}$ There has been speculation (Traill 2008) that such restraint may have been a deliberate strategy to avoid an overt clash (over "metaphysical Kantian theory") against the overenthusiastic positivism which dominated during most of his lifetime. Nevertheless he did occasionally offer such comments (within restricted domains):
} 
fanfare that mainstream philosopher-epistemologists mostly unaware of Piaget - have recently reinvented recognition of this admittedly Kantian strategy as "Predictive-Processing" with its own jargonvocabulary). So Piaget became best known rather for the clinical successes which resulted from this arcane theory.

Anyhow that leads to at least two likely practical encoding mechanisms, often operating concurrently:

(i) Inherited traits: Some tatons must have been inherited (simply transcribed from the DNA) having evolved with the species in a Darwinian fashion, and hence treated as basic essentials. ${ }^{10}$ (Such inbuilt "know-how" roughly matches Kant's notion of the "Synthetic a-priori" — and PP's "prior").

(ii) Learnt sensorimotor knowledge $\left(\mathrm{M}^{0} \mathrm{~L}\right)$. This tallies obviously with Piaget's infant studies where the child performs random actions and discovers useful environmental facts by such trial-and-error during play.

Note that such play is also a Darwinian-like exercise though now in the brain-domain (instead of speciesevolution) - apparently selecting and linking tatons and their schèmes. Many tatons lacking an inherited "(i)-type" preset role, can thus be seen as "useful-junk" or "wild-card" candidates for possible selection-\&/ormutation, mostly provided as "deliberate" $n c R N A$ extras from the DNA coding. However we will consider another source of such "useful-junk" later, in $\S 6$.

\subsection{Address-Codes and How used?}

How does a complex system know how to contact some selected destination or subgroup? The solution offered here uses the "combination-lock" precedent of "phone-number" or of an internet-URL — though without necessarily being so rigorous, and indeed subject to Trial-\&-Error adjustments. (And of course immunology depends on a comparable recognition system).

One might instead suggest "just send the message down the right channel" - but then how is the system to know which is the right channel? Does the channel have a name-or-number-or-description-or-vector? In which case we still need to encode that.

E.g.(i) “Whenever one reads the main 'logisticiens', such as Russell, Wittgenstein, Carnap, etc., one quickly realizes that they all depend on certain intuitions: - intuitions which are taken for granted, exactly in proportion to the extent that they evade verification." (Piaget 1949 [transl.RRT])

(ii) He deplored the compartmentalization of Science-vsPhilosophy as "catastrophic" for both; (Piaget 1970a, p.64).

9 "Predictive Processing" i.e. "PP", alias "Predictive Coding". See Clark (2013) - including open discussion on pp.25-53, with the only slight reference to Piaget on page 39,

(by König et al.). Clark's general response is on pp.53-64.

${ }^{10}$ Genetic loss of key items would presumably be lethal and usually lead to miscarriage or still-births. Less serious omissions probably account for autism-spectrum disorders and suchlike - where compensation may be possible by subsequent learning of the desirable missing skill.
Then again, we might just be content to wait for periodic "I'm here" advertising-messages from the destination (a local causal-inversion by trial-\&-error). But that too has its technical and practical problems, especially for fast performance, so let us just focus provisionally on the above-mentioned combination-lockor-phone-number model - which is at least known to work for other bio-tasks.

\subsection{Relocating a "written" memory undamaged?}

Memory locations are known to change. But how could such "House-Moving" occur without causing damage to (i) linkages, and (ii) the memory itself?

If a practical concept can indeed be held by a "choir" of semi-cloned RNA-schémata - then calculations show that this whole ensemble would still be small enough to fit within one of the many virus-sized "capsids" "11 which are now known to be readily available $A N D$ highly portable. Failing that, very-many such ensembles (and capsids) would fit inside a neuron, and such new neurons are known to flow away from the hippocampus in certain circumstances. (Traill, 2019; §5.4, p.12).

In contrast, any such [A]-encoded "writing" (built from axon-circuit loops) could hardly be moved without ripping it out of its matrix.

Meanwhile if the [R]-type quorum has remote links to archive material, and if the relevant contacts are indeed made through URL-like addresses, then it would effectively be using a mobile telephone! - and location would no longer be crucial for linkage-arrangements! ${ }^{12}$ - That sounds far-fetched, but is there any alternative consistent with the requirements? Of course there might be some sort of compromise, with locally-limited domains for the "mobile phones" (akin to the concept of "Local Area Network" - "LAN"); but the basic concept still seems applicable.

And note that this is all made apparently feasible by the postulated ultra-micro environment of digital-RNA,

\footnotetext{
${ }^{11}$ Capsids range in diameter-size from about 10 to $2000 \mathrm{~nm}$ (Zeltins, 2013; Božič et al, 2013). The volume-capacity calculations (Traill, 2019) are based on a herpes virus of $125 \mathrm{~nm}$. Viruses like SARS and COVID-19 use somewhat smaller capsids of about $60 \mathrm{~nm}$ (Goldsmith et al, 2004). Capsid-assembly is discussed by Reed et al (2018).

It seems that most references to "granules" can be taken as referring to capsids, e.g. Kanai et al (2004), Becker \& Gitler (2015), Elvira et al (2006), Moujaber \& Stochaj (2018).

12 Another example-type: Cobb (2020) reviews cases of brain damage where the affected facility then relocates-andrecovers (or reconstructs) away from where our brain-maps report. That seems mysterious if we think the location is crucial, but not if we emphasise coded callsigns instead, (as with mobile phones). The "standard" locations may be organisationally convenient but not essential, like office organisation altered after a fire. - Historically our knowledge of this location-plasticity goes back to Lashley (1924, 1929).
} 
and photon/optics-based messages - concepts which partly stem respectively from the work of Hydén in the 1960s, and Gurwitsch in the 1920s; e.g. Hydén (1967b), and Gurwitsch (1924a,b).

The residual main issue is: How could such "writtendown" 3D memories get to be selectively relocated to a remote cortical site such as the prefrontal lobes:

\subsection{Moving Memory to the remote Cortex}

The specific problem of: How to physically "ferry" short-term memories (STM) in the hippocampus, several centimetres into long-term memory (LTM) in the cortexarchive? This raises some intriguing questions which we can return to in Part B (page 13 below), but as they are somewhat peripheral to our main theme of intelligence, they need not be discussed in this present "Preview" section. (After all, our main concern here was about: "How the 'filing cabinet' can realistically be filled", and not with "How it is then moved to another building"! And yet that extra investigation does turn out to be illuminating, as we shall see).

\subsection{Gut Microbiome affecting the Brain}

A recent surprise-development indicates that the gut's microbiome population can have important effects on mental functioning, e.g. see Cryan \& Dinan (2012), and Dinan et al. (2014). One comparatively orthodox type of explanation involves enzymes \&/or bacteria (beneficial or not), and their invasion of brain-parts - either physically or via influence on the vagus nerve (Forsythe et al., 2014; Suarez et al, 2018).

A parallel possibility, suggested by the present project, is that the gut microbiome would doubtless be able to produce-or-acquire ample supplies of "junk" RNA - a possible complicating factor in the schemoiddynamics postulated here. - More details in $\$ 6$.

\section{The Same Topics in More Detail}

\subsection{Theory, Empiricism, or Both-if-feasible?}

This choice is fundamental to Epistemology "How can a system build up its knowledgerepertoire, (despite having ultimately startedancestrally with nothing but whatever arbitrary 'a-priori' guidance-coding was available to it at the time)?" And that a-priori seed-coding could just be arbitrary junk which happened to be in a suitable format, see Traill (1999, ch.4) - allowing huge numbers of "wasteful" failures among underlingelements, as long as there is the occasional success. — Only possible for comparatively simple $\mathrm{M}^{0} \mathrm{~L}$ tasks or sub-tasks.

(No coincidence if that sounds like theories about the beginning of - life itself: (i) - which too, is an epistemic system, working on similar Darwinian trial-\&-error principles. (ii) The - Immune system is another such. Meanwhile our concern here is with the remaining two of the big four: (iii) The Individual Brain, and (iv) how - Society seeks to gain its collective knowledge i.e. "Scientific Method." See Popper (1975), Traill (1999, ch4; 2008), and works of the immunologist N.K.Jerne (1911-1994): (Jerne, 1955, 1966).)

To aid survival, it helps greatly if such a system can advance beyond that inherited a-priori coding initially using much "wasteful" trial-\&-error. In the brain such processes imply the competitive selection of suitable schéma-mutants during "sensorimotor" play, whereas other schémata (e.g. for essential reflexes) may be taken as inherited fixtures.

Likewise in Society/Science, some ideas may be taken as "facts", while others are taken as currently worthless, though maybe arbitrarily mutatable until such time as they seem to fit practical requirements (even if there is no insight as to why).

There are some important side-issues relating to the four abovementioned epistemic domains, but we can here focus on the two most relevant:

(iii) the Brain and, (iv) Society-as-such — both capable of advancing through $\mathrm{M}^{0} \mathrm{~L}$ (sensorimotor) to $\mathrm{M}^{1} \mathrm{~L}$ and beyond. There is clearly some overlap between (iii) and (iv), and indeed there is often no obvious distinction drawn between them.

Sometimes that hardly matters insofar as they seem to operate according to very similar principles (as discussed in Traill (1999. ch4; and 2008, p.31)), but it can-and-does cause confusion on important issues. In particular, a public-language (like English or Thai) has very different roles in these two domains:

In the Social domain, words-or-phonemes are the basic $\mathrm{M}^{0} \mathrm{~L}$ elements (analogous to schèmes in the brain); whereas in that individual brain, words are late-comers derived from schèmes — schémaconstructs belonging to $\mathrm{M}^{1} \mathrm{~L}, \mathrm{M}^{2} \mathrm{~L}$ and beyond (along with other derived symbols).

Most philosopher-epistemologists seem unaware of this distinction - taking words and recognised languages as the basis for thought, (which is appropriate for society-as-such, but not for individual thought). This may not matter too much if they are focussing on society, as they usually are; but Fodor $(1975,2008)$ has at least promoted the idea of a separate "Language of Thought" ("LOT") which takes orthodox philosophy some way toward the schème concept. 
Philosopher-epistemologists also often seem to be ambivalent about "Truth" — what exactly that word means, and how truth (or near-truth) can be accessed. By the 1970s, Quine's (1951) critique did ultimately win against the perfectionist policies of Carnap and the Vienna Circle (Creath, 1991). But despite that, philosophers are still commonly defining "knowledge" as "Justified True Belief" (JTB: without explaining "true belief"!). That leaves "knowledge" poorly specified - because by this definition it has to be true, whether one knows that detail or not! (e.g. Lacey 1976, Lemos 2007, Sankey 2008). And since epistemology is the "Theory of Knowledge", that too is left ill-defined by them!

Worse still, it seems the Scientific community has largely followed suit, continuing to blindly follow such perfectionist thinking, unjustly seeking clearcut laboratory evidence whilst largely ignoring persuasive theoretical findings - instead of at least further investigating them in depth. E.g. see the critique of a superficial "debate" over insect navigation (Traill, 2005c).

Popper (1934) famously emphasised the need to test hypotheses - and it should now be clear that this closely resembles the idea of Darwinian selection (i.e. testing!) - the ubiquitous default strategy, at least for $\mathrm{M}^{0} \mathrm{~L}$ situations. As such it is clearly on the right track, but there are two vital criticisms to be made:

(1) "Testing" need not always be empirical (despite Vienna Circle views). Piagetian equilibration (coherence seeking) is another powerful test; also induction and analogy are tools we unconsciously use all the time (even in $\operatorname{logic}{ }^{13}$ ), and are inescapable from a Piagetian viewpoint (at least regarding the individual, but arguably also for science-as-such). ${ }^{14}$ Popper's oversight regarding

13 "Our reasons for believing logic and pure mathematics are, in part, only inductive and probable, in spite of the fact that, in their logical order, the propositions of logic and pure mathematics follow from the premises of logic by pure deduction." (Russell, 1924, p.362) — as quoted by Cushan (1983/2014, Ch.5, endnote 2). She then adds:

'See also Lakatos (1978), p.130, esp. n.2, where he comments that both mathematical proof and inductive generalisations are "content increasing" and hence involve induction. See also Salmon (1967), p.19, and Hempel, (3) in Hempel (1965), p.29.'

${ }^{14}$ However the validity of such $\mathrm{M}^{\text {high }} \mathrm{L}$ tactics should depend on one's objectives. Here the aim has been towards better understanding; but if one is instead concerned mainly with clinical application, then clearly a more empirical approach is needed, at least in the short term. Similar distinctions also need to apply in legal matters, including the difference between civil and criminal cases. Such distinctions also apply regarding prediction (Traill, 2015). inappropriate cases accords with his attempt at transcendent perfectionism.

(2) Popper discounted the need for constructing hypotheses saying in effect: any will do, as long as they are testable. That is no doubt true for simple $\mathrm{M}^{0} \mathrm{~L}$ situations, but intelligence usually enables us to do better. Thus note that intelligence (the topic of this paper) is embodied in the higher levels $\mathrm{M}^{1} \mathrm{~L}_{-}$ $\mathrm{M}^{2} \mathrm{~L}-\mathrm{M}^{3} \mathrm{~L}$, and its short-cuts are needed if we are to avoid the crippling inefficiency of default-minimal pre-intelligence!

Here we are referring mainly to the Social Domain with its lingering trial-\&-error Popperian "Scientific Method" which (if followed strictly) could take, e.g $>\mathbf{1 0}^{\mathbf{2 9 1}}$ centuries to solve a simplebut-nontrivial combination-lock problem (thus effectively unsolvable by this pure $\mathrm{M}^{0} \mathrm{~L}$ method): (Traill 1978, §C1.2) after Ashby $(1960, \S 11 / 5){ }^{15}$

As a start, the system could then add the simple $\mathrm{M}^{1} \mathrm{~L}$ strategy of systematic sequencing, so that it never wasted effort in repeating the same test.

However for further improvements the system would need some insight on any likely patterns in the distribution of possibilities (as offered by those wellconsidered theories which Popper tended to dismiss), thus enabling helpful guesswork - then available for real-life testing.

Anyhow such social-research principles would also apply to the Individual-Brain Domain.

Consider such RNA coding-strips as "microtext." If such elements (or "choruses" of them) do serve as Piaget's schèmes, then it is obvious to imagine that each RNA-coding-strip will have a straightforward text-like organisation - like $\bullet$ a written sentence, or - strip of recording tape, etc.

In particular we might best see it as a $\bullet$ strip of "computer-programming" for a contingent action of some sort (referred to as a "taton" $" 16$ in $\$ 3.4$ above), in the spirit of Piaget's theory.

\footnotetext{
${ }^{15}$ Such principles apply to the theory of effective password security: (number of choices in each place)(how many places) (the number of overall possible solutions)

soon becomes impossibly large unless perhaps one can reasonably guess at likely lazy short-cut passwords, such as "AAAA3333" (Such reasonable guesses can likewise help to break down complex science-problems).

Note that, for the comparatively simple mechanistic laws of pre-quantum physics (pre-1901), the Popperian approach is approximately correct. (I.e. when it is nearly valid to take observations at face-value). Coarse analysis of social sciences, like macroeconomics are also justified in such use, wherever genuine micro-studies are impossible. But of course that approximation breaks down for complex models which are concerned with mechanistic basic mechanisms.

${ }^{16}$ It is convenient to name such strips functionally as "Tatons," which emphasises their supposed role, and avoids fully prejudging their apparent RNA identity. (But whenever we
} 


\subsection{RNA-coding needed for Advanced Intellect}

Significantly it may also thereby be like - a standard protocol-coding for the internet (as we shall see). Anyhow we may depict it as something like fig (i), (as depicted in Traill (2019)):

[Label | Switches | Program

Figure (i). Putative layout of a "Taton" static-coding along a relevant strip of RNA (underlying a "schème"). In practice, the restrictive "gates" within "Label" and

"Switches" might sometimes intermingle

Here "Label" encodes the "URL, address, or phone-number" to identify it selectively; and "Program" supposedly issues signal-patterns for the relevant action, dependent on whatever other choir-members are doing at that instant.

See Fig.(ii) (below) for the fairly obvious course of the signal-traffic during either match-or-mismatch.

The Fig.(i) configuration is theoretical, but note its formal similarity to the experimentally determined architecture in typical $m$ RNA sequences: Their 5'-or-"head"-end consists of an "untranslated" (UTR) segment, while the 3'-or-"tail" has a longer UTR section terminated by a multi-A (...AAAA) segment. (Barrett et al, 2012; Michelson \& Orkin, 1980). That invites detailed examination and evaluation of any supposed tatRNAs (tatons), and of their postulated "labels." As a start, note that "neuritin $m$ RNA shows different localization elements for CNS versus PNS axons; its 3' UTR drives localization in the hippocampal neurons neurons and 5' UTR drives localization in the sensory axons." (Merianda et al, 2013; my italics).

But meanwhile an important new idea here, is the suggested intervening "Switches" section. Like epigenetic add-ons controlling DNA-expression, these segments could consist of various switches to block-or-permit the activating signal to pass. And those switches could respond to the presence-orabsence of various mood-affecting chemicals.

This arrangement might help to explain the mechanisms of such outcomes (with reversible switching for short-term, or one-way switches for long-term). That could account for certain aspects of addiction, habituation, or trauma. It might also help regarding Freudian repression and maybe even conscious suppression.

do accept that RNA-identity, a word like "tatRNA" or "actRNA" or "action-RNA" may be better). See Traill (2008). ("Tat" is German for action or deed).
As for this signal (seen as travelling along the taton's program segment), it is not yet clear what form or forms this might take. As a working hypothesis its flow can be taken as excitons or phonons - a quantised internal vibration through the RNA-structure. However it could also be, at least partly, an electon-flow or some other chainreaction phenomenon - (but of course it would not be anything so observable as its [A]-system analogue, the AP spike).

Here it might be useful to consider the phononflow (etc.) work of the late Ukranian physicist Alexander Davydov (1912-1993), though he was more concerned with the rapid flow of bio-energy rather than any messaging possibilities. The submolecular details of his approach are beyond the scope of this paper, but fig.(ii) outlines the type of system to be considered.

Note some resemblance to how code is read from $m R N A$ to construct a physical structure (a protein molecule), each-time with the help of a ribosome "mini-factory." - However that is an arrangement dependent on a supply of molecular raw-material, perhaps subject to logistical delay (acceptable for "building-works." But such delays would crucially disrupt the real-time messaging or optical effects considered here).

For this contrasted situation of "action-RNA"readout, the only raw materials needed for performance would be energy \&/or electrons which would be less subject to arbitrary delay, and not needing any "factory" - which indeed would probably just get in the way of its real-time urgencies.

In fact any local unexpected absence of ribosomes could be a helpful clue in distinguishing tatons from mRNA; e.g.

- "although ribosomes are present in growth cones of hippocampal neurons, they are not numerous" (Deitsch and Banker, 1993). - There must be relatively few ribosomes to go around for the large, heterogeneous population of mRNAs that seems to exist." (Steward, 1997).

(That heterogeneity might itself also be a clue). Also, quoting Deitsch and Banker directly: "ribosomes are present in dendrites but excluded from axons" - though that might relate to their in vitro conditions.

\subsection{Signals between RNA-sites}

What signals go between those micro-sites? Consider the familiar voltage "spikes" of AP signalling (as used in the synaptic $[\mathrm{A}]$ system). Could that also be used for the [R]? Not really! Those millisecond spikes would be much too coarse- 
and-slow to take direct advantage of the fine structure within RNA.

Such micro-sites are instead well suited to quantum jumps in the infra-red (IR) range of frequencies. (Each such IR wave has time-period of about $10^{-15}$ seconds - vastly faster than the mere $10^{-3}$ seconds for the AP spike — virtually a different world!)

\section{— Figures (ii) and (iii)}
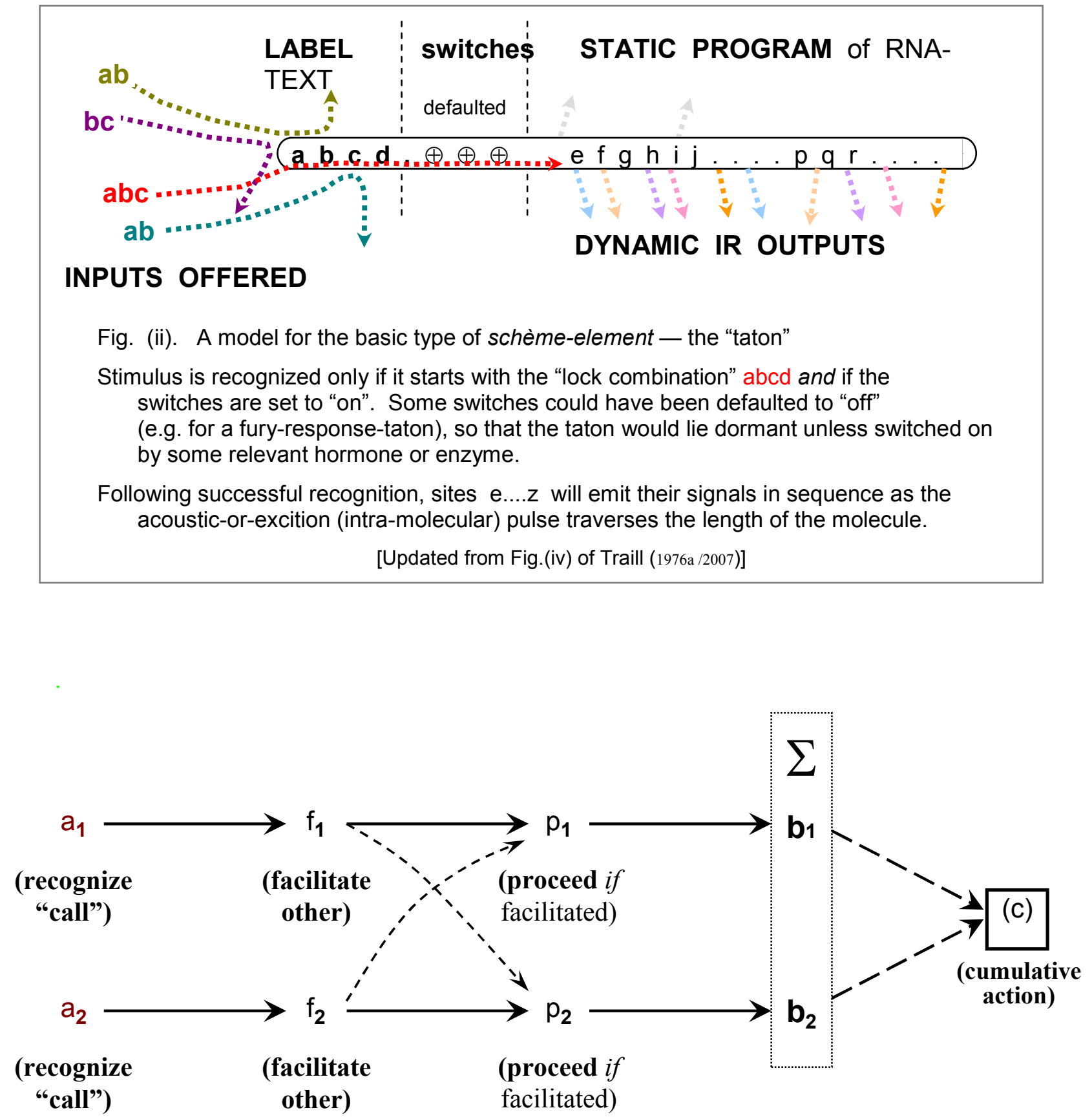

Fig (iii). Illustration of how the individually-insignificant micro-elements may collectively cooperate, under favourable circumstances, to produce significant behaviour - synchronised even in cases when the synchrony of $a_{1}$ and $a_{2}$ cannot be relied upon. (Other arrangements may also suit). Only two tatonelements are depicted here, but the concept should be thought of as applying to a somewhat larger number - probably involving a threshold concept, in that only when there is a sufficient active population with sufficient unanimity and synchronization, will the behaviour actually take place. [Here $b_{1} \& b_{2}$ are now expressly allowed minor (temporary?) differences, but the diagram is otherwise based on Traill (1978b, fig.C5.2/2) — with the cross-feed-coordination concept borrowed from Monod \& Jacob (1961).] 
That tentative conclusion inspired a search for other evidence of IR, and it was quickly realised that the shape and dimensions of myelinated nerve-fibres suggested their likely use as coaxial cables for IR, like the cables for a TV-set using broadcast wavelengths. (Traill, 1976a).

Of course myelin already had a recognised vital role in AP-propagation, but this new insight suggested that its fibres had a dual role, now including IR-transmission ${ }^{17}$ — so now apparently serving the two separate systems simultaneously; (Traill 1976a, 1978b, 1988, 2011).

There was also confirmatory circumstantial evidence: (a) that IR emissions had been detected coming from active nerves (Fraser and Frey, 1968); and, (b) largely unknown to the English-speaking world there had been much interesting work on biological "Ultra-weak Photon Emissions" (UPEs) triggered by the work of Gurwitsch (1924a,b). See Cifra \&Pospíšil (2014), Cifra et al. (2015).

Much more recently, more direct evidence indicates that optical signals can indeed be carried via myelinated nerve-fibres (Sun et al, 2010), though they offered a more chemical-based explanation, without any reference to coaxial cables as such. Significantly though, they showed that they needed to block BOTH optical AND AP signals in order to stop the message getting through. That strongly suggests that both modes may be operative under suitable conditions. However it is also important to note that they were testing peripheral nerves - and we shall see that it may be prudent to distinguish those from CNS fibres ${ }^{18}$ deep within the brain itself - our present concern.

(Here we can overlook the extra in-between category of other less centralised CNS-fibres. These

\footnotetext{
${ }^{17}$ As a possibly significant side-issue here, consider this quote from Fuster (2003, pp.32-33) "Flechsig ... concluded that the functions of the various cortical areas develop following the sequence of their myelination. Thus ... The prefrontal cortex... would be destined [for] ...late-developing and complex ... functions (e.g., language). We know that this is indeed the case, but the role of myelin in the process is far from obvious." [My emphasis].

Comments: (1) Such developments would presumably play a part in facilitating a step to a higher Piagetian stage. So: (2) Insofar as such myelin allows "[R]" effects outlined in this paper, then myelination's likely role becomes less mysterious.

${ }^{18}$ Significantly perhaps: myelin is produced differently inside and outside the brain itself - by multi-tasking oligodentrocytes within the Central Nervous System (CNS) - but by single-tasking (1:1) Schwann-cells for the Peripheral Nervous System (PNS). Diameter ranges also differ in a significant way (Traill 2005a, §5).
}

may have specialised needs which we can bypass here - e.g. for dealing directly with input-reception or output-assembly, as a go-between for the PNS analogous to a "driver" subroutine in computerprogramming).

As mentioned in $\S 3.3$ above, such optical transmissions would not necessarily be totally bound to travelling via those myelinated nerves (unlike the AP spikes). Other fatty tissue might suffice, and nearred wavelengths (around $0.8 \mu \mathrm{m}$ ) could also travel through watery media. However most wavelengths longer than about $1.5 \mu \mathrm{m}$ would be heavily hampered by such aqueous media. (Traill 1976a; $1988 \$ 2.2 \&$ ch.3; 2000; 2005a; 2010a $\$ 2, \S 2.2 ; 2010 \mathrm{~b} \$ 3.1 .2)$, Chamberlain et al (1966), Ray (1972), Robertson et $\mathrm{al}^{19}$ (1973), Zolotarev et al (1969).

\subsection{Need for Managed Redundant Coding}

As already noted, redundancy is necessary as a security measure to reduce destructive unruly actions caused by errant individual sources. (It may also be needed to ensure adequate optical coherence). That need adds new complications of how to organise this resultant ensemble of "near clones" and the "votingprocedures" regarding the collective decisions. See Fig.(iii). Meanwhile such decisions will presumably then be transmitted by encoded IR (or perhaps using other nearby optical wavelengths).

If repeated rehearsal eventually results in closeenough unison among $b_{1}, b_{2}, b_{3}, b_{4}, \ldots$ etc, then we might expect a tidy-and-stronger collective resultant effect at "(c)" - which could well take the form of an artificial laser beam, - or else a redundancy which can greatly sharpen the details of a transmission (Hamaker et al., 1977): the technique which led up to the WiFi patent (O'Sullivan et al., 1996).

Laser beams are usually obtained from light waves reverberating synchronously to-and-fro, due to stimulated emission within a two-mirrored cavity. - However such synchrony, or something more sophisticated, might instead be possible from a wellrehearsed arrangement like that of Fig.(iii) - possibly also involving optical interference special-effects.

Anyhow it seems reasonable to suppose that basic motor-skill-development may entail gradually getting such details correctly sorted out for each skill. - That is presumably focused on $\mathrm{M}^{0} \mathrm{~L}$ activity, but the same principle probably also applies to advanced-thinking skills (at $\mathrm{M}^{1} \mathrm{~L}-\mathrm{M}^{3} \mathrm{~L}$ ). However that is likely to be less straightforward due to the increased connections-complexity of higherlevel schémata - see $\S 4.5$, which follows:

\footnotetext{
${ }^{19}$ listing the bands most likely to survive water-absorption as: $<2.7 \mu \mathrm{m} ; 3.5$ to $5.8 \mu \mathrm{m} ; 6.9$ to $9.1 \mu \mathrm{m}$; and $>100 \mu \mathrm{m}$.
} 


\subsection{Address, Message, and Structure Links}

4.5.1 How to Find and "Talk to" Distant Sites?

How could the brain find its physical "writtendown" encoding of Memory X? Strategies might involve: (1) The trivial case of immediate chemical attachment; (2) Arbitrary scan-search, (if we can find a plausible scan-mechanism for it!);

(3) Systematic scan-search, keeping track of "the search so far" (if we can also find the extra mechanism for being systematic - presumably an $\mathrm{M}^{\text {higher }} \mathrm{L}$ schéma). Or:

(4) Direct dedicated nerve-link? Current assumptions seem to be that if a message has to pass from A to B (or back again, as a reply etc.), then there must be a direct dedicated fibre-cable link from $\mathrm{A}$ to $\mathrm{B}$, and that the sender at $\mathrm{A}$ will SOMEHOw know which is the right fibre-cable. But that "knowing" implies a code-name of some sort, so the problem of coded-choice persists. Moreover that fibre might allow only "one-way traffic" even for [R]-signals, (Traill 2019, footnote 21) thus forcing any return message to take a different route - also codespecified as a RETURN-ADDRESS!

(5) However, if this time-based message has indeed been adequately code-addressed, then any competent set of cables should suffice as long as there is some IR-optically sound pathway for the message. The internet clearly indicates the feasibility of that arrangement, so we may provisionally accept it as possible (and maybe necessary), especially for "long-distance" messages of perhaps $15 \mathrm{~cm}$ across the brain. But of course this does seem to commit us to accepting the need for coded-addresses - ( unless we are to be left with a still-unresolved problem until we find some better explanation).

(6) Nevertheless such address-coding need not necessarily be precise. At least sometimes it may suffice for it to be a call (initially?) to "ANY schème(s) involved in 'ball-catching', or 'mouthopening,", or nostalgic memories - just as advertisements (in the Social Domain) may simply address "ANYONE interested in: chocolate, or injustice, or Manchester United Football Club". (Indeed we might well draw useful further analogies from the advertising industry, perhaps including its recent pathologies).

A useful variation would be when any part of the brain-memory "P" (not necessarily central) puts out a spontaneous call "for 'anyone' interested in dialogue?" If that elicits an (addressed?) reply from "Q", then a dialogue \&/or partnership can be set up, at least temporarily. That has a computer analogue in the connection between two Bluetooth devices - or Skype clients.
(7) We need not rule out other possibilities.

The above cases mostly emphasise the links between well-separated schémata. Now we need to consider possible links within such schémata; though these will tend to be structural links, rather than conversational (at least initially): -

4.5.2 Augmenting Chemical-Links within a Schéma

Shorter distances within a complex schéma have other complications relating to schéma cohesion, etc: $\mathbf{M}^{\mathbf{0}} \mathbf{L}$ supposedly installs schèmes (\&/or their component tatons individually) into schémata. Structurally that ensemble is likely to take a chemical form (as in "(1)" above), involving hydrogen bonds or suchlike - all identifiable as being in essentially the same location (even perhaps allowing for redundancy). But with the development of $M^{1} L$ 's overseer-role, those (nowsubsiduary) $\mathrm{M}^{0} \mathrm{~L}$-schémata will need to gathertogether in a wider cluster (in some sense). This might still involve pseudo-chemical bond-links, though that would seem less satisfactory.

Other possibilities for this higher stage are discussed in Traill $(2019, \S 6.2)$, but short-range photon exchange ("virtual links") begin to look more attractive.

\subsubsection{Beyond Chemical-Links}

Then by the time we get to the top level involving $\mathbf{M}^{3} \mathbf{L}$-schémata in humans, mere chemical clusters will usually be out of the question. Indeed there will often be a need to coordinate sub-concepts located in different parts of the brain, often far apart, so that is where the myelinated coaxial fibres could be playing their key role via addressed messages.

E.g. I could be assembling new schèmes within my Hippocampus, trying to gain a coherent concept, but this concept might only begin to make sense if I incorporate some of my previous knowledge (such as "object"-concept) now archived in my Cerebral-cortex - But how could I access that? An in-principle solution would be to use a "virtual" linkup, with the relevant link-addresses then saved as part of the focal concept (still currently centred as "working memory" in my hippocampus).

Note that consideration of actual physical location is then no longer crucial, and that opens up new possibilities:

\footnotetext{
Having provisionally concluded the basics of what a schéma is, and how it gets into its "filing-cabinet" in the hippocampus (to use the analogy of \$3.8), we will now enquire into how that "cabinet" can be usefully relocated "into a different building".
} 
New section numbers are used beyond here in this 2022 updated version

\section{Part B - Relocating the New Intelligence Coding}

\section{Storing Code to LTM in the Cortex}

\subsection{New Memory-Records do Re-locate}

Details of memory-processing are offered in Traill (2019, §7.2-\$7.3.1; incl. Fig.2). Put briefly: it seems there can be a sort of production-line sequence (Rakic 1975, 1985, 2007), somewhat like the following (though there is probably significant variation):

Various INPUTS $-(\mathbf{1}) \rightarrow$ ATTENTION CENTRE ${ }^{20}$ (with "immediate ${ }^{21}$ memory" of the here-\&-now only). -(2) $\rightarrow$ HIPPOCAMPUS (with "working 21 memory"). $-(3) \rightarrow$ CEREBRAL-CORTEX (with Long-Term Memory, "LTM").

Thus any patient with bilaterally ablated hippocampus can at least still deal with the "here-and-now" (presumably made coherent by adding temporary ad hoc schémata) whilst also remembering the distant past (pre-surgery). But that patient completely forgets the interview as soon as the topic moves on; (Scoville \& Milner, 1957).

For Long-Term Memory, the key point here is that concept-coding apparently has to travel between sites (notably out-of-the-hippocampus into a distant "archive") - so we need to consider how that could be possible without destroying that coding and its linkages. So let us look at the steps:

"...-(1) $\rightarrow$ ATTENTION" seeks to integrate the comparatively raw data (not hitherto meaningfully structured) - presumably encoded mostly via traditional AP, although (e.g.) IR coding also seems a viable alternative. (Not really relevant here, though a collection of interesting topics in its own right - and probably involving the thalamus.)

“...-(2) $\rightarrow$ HIPPOCAMPUS". For any schèmestructural information which has to be transferred here (from attention-centre to hippocampus). This could conceivably be (i) by IR-coded signals (though that would then inconveniently raise the "writingdown" problem of $\$ 3.2$ and its footnote 4 $(+\S 3.5)$ above, unless messages were very simple).

\footnotetext{
${ }^{20}$ Location uncertain

${ }^{21}$ Taking immediate-memory ("imM") and working memory ("wkM") as collectively constituting Short-Term-Memory ("STM")
}

More likely, (ii) actual physical schème-like structures could flow to the hippocampus from the mysterious "attention centre" which would then probably need to be situated very close-by.

(iii) A third possibility is that there is no such flow, and that the hippocampus does its own independent constructing during events (thus "reinventing the wheel" each time - whilst addingand-applying its own mental substructures as part of the Piagetian assimilation process).

Neither journey " $-(1) \rightarrow$ " nor " $-(2) \rightarrow$ " need detain us further here, but the STM-LTM stage ("-(3) $\rightarrow$ ") is of some perplexing topical importance, with some significant implications:

\subsection{Rakic's Neuron-Migration to the Cortex}

"Only in the brain ...specific cell classes are generated in one place and then subsequently migrate to the very precisely designated final position. This is particularly evident in the cerebral cortex where postmitotic cells migrate long distance and bypass each other before settling in the final position within specific layer within a given radial column." (Rakic 2007, p.206). -

Other references in Traill (2019, §7.3.4).

Three relevant items of interest here:

(A) Rakic's diagram ${ }^{22}$ (1988, 1998; Kolk \& Rakic 2022) depicts three different patternconserving bundles of nerve-fibres, each re-mapping its own 2D pattern from three separate brain sources — viz. CC: Cortico-Cortical; — TR: Thalamic Radiation; - and NB+MA: NucleusBasalis + MonoAmine centres.

(B) But more relevant here: His diagram also shows a similar pattern-conserving bundle of glialfibres (NOT nerve-fibres) likewise linking to that cortical-column matrix, but coming from the ventricular zone (VZ) of the hippocampus.

Moreover these fibres are used as "climbing-poles" by which newly-formed neuron cells climb up to their allocated column in the cortex. That primarily depicts movement during initial development, so it is tempting to guess that this "migration-escalator" might be used in all vertebrates under all conditions.

(C) This migration could obviously help as a "taxi-service" for RNA-tatons (either in capsids within the migrating neuron, or maybe just loose in that cell). That would neatly offer a mechanism for

\footnotetext{
${ }^{22}$ It may be of some interest to note a similar arrangement for the compound-eye nerves of drosophila fruit-flies (PintoTeixeira et al., 2018), though it is not yet clear what conclusions might be drawn from that.
} 
the mysterious translocation - which seems plausible for some vertebrates.

Yet in humans this flow has ceased by adulthood (Rakic, 2007; Sorrells et al., 2018; and Weiler 2018).
Likewise for dolphins (Parolisi et al., 2018). And yet healthy adults do still archive memories in the cortex! But how?

\section{Table A}

Choice of feasible routes (for an intact Schéma) going from Hippocampus to Cortex

\begin{tabular}{|c|c|c|c|c|c|c|c|}
\hline & \multirow{2}{*}{$\begin{array}{c}\text { "postage"-packaging } \\
\text { of embodied } \\
\text { molecular } \\
\text { encoding }\end{array}$} & \multicolumn{6}{|c|}{$\begin{array}{c}\text { Candidate pathways for delivering hippocampal molecular-encodings to cortex "archives" } \\
\text { - where these "written postal-packages" remain intact throughout transmission }\end{array}$} \\
\hline & & $\begin{array}{l}\text { New neurons (or smaller } \\
\text { "parcels”) climbing Rakic's } \\
\text { glial-threads to the cortex }\end{array}$ & $\%$ & $\begin{array}{c}\text { relevant nerves: } \\
\text { kinesin parcel-transport } \\
\text { through axons }\end{array}$ & $\%$ & $\begin{array}{l}\text { blood circulation } \\
\text { serving as } \\
\text { "parcel-postage" }\end{array}$ & $\%$ \\
\hline \multirow{3}{*}{ 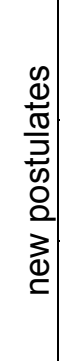 } & $\begin{array}{l}\text { whole neurons } \\
\text { (supposedly } \\
\text { containing schémata) }\end{array}$ & $\begin{array}{l}\text { (a) yes (for infants), } \\
\text { but no guarantee they } \\
\text { carry any new schémata }\end{array}$ & \begin{tabular}{l|l}
9 \\
$?$
\end{tabular} & $\begin{array}{l}\text { (b) impossible! } \\
\text { (neuron within axon!!) }\end{array}$ & 0 & $\begin{array}{l}\text { (c) BBB would } \\
\text { probably obstruct any } \\
\text { whole migrant neurons }\end{array}$ & 5 \\
\hline & $\begin{array}{l}\text { capsids: virus-like } \\
\text { (containing schémata) }\end{array}$ & $\begin{array}{l}\text { (d) capsids unlikely } \\
\text { as glia-climbers }\end{array}$ & 4 & $\begin{array}{l}\text { (e) by kinesin/dynien on } \\
\text { micro-tubules in axons } \\
\text { (direct? or in stages?) }\end{array}$ & 51 & $\begin{array}{l}\text { (f) if BBB allows capsids } \\
\text { to pass through - both } \\
\text { into blood, then brain }\end{array}$ & 19 \\
\hline & $\begin{array}{l}\text { loose schémata } \\
\text { (taton ensembles) }\end{array}$ & $\begin{array}{l}\text { (g) very unlikely } \\
\text { as glia-climbers }\end{array}$ & 1 & $\begin{array}{l}\text { (h) On micro-tubules, } \\
\text { likewise . Maybe; but } \\
\text { perhaps too untidy?? }\end{array}$ & 21 & $\begin{array}{l}\text { (i) Maybe; but prob- } \\
\text { ably too vulnerable? }\end{array}$ & 2 \\
\hline $\begin{array}{l}\text { old } \\
\text { idea }\end{array}$ & $\begin{array}{l}\text { concept-code seen as a } \\
\text { synapse-configuration } \\
\text { (still the orthodox view) }\end{array}$ & (j) impossible! & 0 & (k) impossible! & 0 & (1) impossible! & 0 \\
\hline
\end{tabular}

If a species loses some apparently-useful faculty during evolution or life-cycle, it is likely that there is some good reason which benefits survivors, through removing a feature which (on balance) is now more trouble than it's worth. That probably means either (i) that its role is no longer valued, or (ii) the species has found one or more better ways to perform that role. Given the continued cortex-archiving, "(ii)" seems to be the answer here - and hence the question "What better solutions could the species have found?"

Indeed maybe Rakic's glial-climbing activity was a false lead here anyhow. - I.e. nothing more complex than the obvious supply of "still-empty" new neurons to the cortex, (not yet loaded with any newly-formed schémata).

In either case we need to look further, and Table A offers a provisional list of conceivable possibilities ${ }^{23}$ (including Rakic's glia-climb), with a subjective rough-estimate (" $\%$ " columns) of the credibility of each. But before discussing those "postage" possibilities, we should have a quick look at current orthodoxy:

\footnotetext{
${ }^{23}$ And such routes could be mutually compatible specialisations, co-existing; e.g. Case-(e) serving fixed specific cortex-sites, while Case-(f) would effectively broadcast the concept "to all interested sites".
}

\subsection{Schéma to the Cortex - perhaps as a mere "Telephone Message"?}

In contrast to the above Table A postulates, the current tacit assumption seems to be that there is no physical transfer of any solid-state "letter" coding. - In fact orthodox opinion seldom even addresses this question of transferring structured information, at least not in adequate micro-detail. If such structures are indeed $\bullet$ somewhat complex, -coded materially, \&/or •entailing essential redundancy, then it is not obvious that mere phonecalls would suffice to move them intact.

For such whole-schéma relocation, the static hippocampal coding would presumably be read off into a set of telegraphic instructions which (if and when they reach the designated site) would then be "written down" as new solid-state coding. This all makes for good Science Fiction as "teleporting" the notional skill whereby our hero is dissolved(!) at location $\mathrm{X}$, while concurrently transmitted-to, and reconfigured at location $\mathrm{Y}$. (Cloning could be a variant on this - leaving the $\mathrm{X}$-version intact).

That is obviously not feasible for real whole humans (even if we could find willing "test pilots"!). But then, might it be possible at the molecular level of encoded concepts? There are two main problems, regarding the two transition-stages: 
(a) Converting from the hippocampal solid-state code into a neuro-signal transmission (whether IR or AP). Such "scanning" might be feasible, applying the emission-pattern principles of Fig.(ii) and Fig.(iii). At least that could perhaps work for [R] systems, using IR to carry the "verbal" copy.

What about [A], the Traditional Action-Potential accounts? No! Any such sophisticated messageinstructions would need to have a digital basis, so any [A] system (using AP-spike statistical patterns) seems an unlikely starter. But even if AP were available for such tasks, we would then have to explain the mechanics of how the code could be translated from solid-static into meaningful APpatterns - the counterpart of Figs.(ii) \& (iii).

(b) The transition from time-based messageformat, reconstituting a new solid-state molecularcode at the new cortical site(s). How could this be done? This enigma is closely related to the "writing down" problem discussed above (in $\S 3.2$ and $\S 3.5)^{4}$ — the Lamarckian task of explicit "tape-recorder" encryption. In principle this is possible, but it does require the design-construction-\&-maintenance of fancy "hardware and software" (and hence the interference by a higher meta-level of organization, as in $\$ 2.2$ above).

Also (be it Lamarckian or Darwinian) this reconstitution would seem to call on the cortex to inefficiently repeat much of the good conceptforming work of the hippocampus - apparently inefficient and prone to unnecessary error, even if feasible.

So now let us get back to Table A, and its listing of conceivable "parcel-post" carriers - relaying the solid coding-structure intact, thus bypassing the immediate need for coding-changes and clever signalling :

\subsection{Feasible "Mail-Services" to the Cortex?}

Table A lists twelve candidates for our consideration, though four are immediately ruled out as untenable; viz. (b) obviously incompatible scales; and (j,k.l - the whole "orthodox" bottom row) since its premise that concepts are held synaptically makes them unsuitable for the three available routes offered in the three given columns - (though someone might perhaps later offer further columns). So let's look at the more feasible cases:

\subsubsection{Case (a) - inside Rakic's new migrating neurons}

This "taxi-ride" inside new neurons has already been discussed in $\$ 4.7$ above, and the conclusion is left open: - It may or may not be part of the answer here (being apparently available for infants, and for adult rodents); but it is certainly not the whole answer.

Bypassing the four unlikely cases ( $c, d, g, i-$ judged $<6 \%$ probability), that leaves several main contenders, perhaps co-existing:

\subsubsection{Cases $(\boldsymbol{e} \boldsymbol{\&} \boldsymbol{h})$ - Axon transport of solid cargo}

Here we have micro-transport using: kinesin-ordynein "lorries" on micro-tubule "roads" (inside axon "road-tunnels"); (E.g. Sleigh, 2019; Maday et al, 2014; Sahoo et al, 2018) — even "hitchhiking" one load on top of another (Salogiannis \& ReckPeterson, 2017).

Kinesins $^{24}$ carry cargo away from the cell-body toward the axon tip (i.e. orthodromically like the AP voltage-spikes), whereas the differently-structured dyneins carry cargoes in the opposite direction (antidromically); (e.g. Vale, 2015). — As far as one can see at this stage, either or both of these mechanisms could be involved here, and perhaps on a largish scale.

Note that: "Fast axonal transport occurs at a rate of 50-200 mm per day and delivers varied cargoes, including vesicles and membrane-bound organelles" (Sleigh et al, 2019). And: “Organelles were observed to move outward from the cell body at 'fast' speeds of up to $400 \mathrm{~mm} /$ day, or $\sim 1 \mu / \mathrm{s}$ '. Hence

(i) any virus-sized capsid (as a "shipping container, carrying ncRNA schémata," see $\$ 3.7$ \& $\S 4.7$ above) should be acceptable as cargo, given that some $m$ RNA is now known to travel this way. ${ }^{25}$ And regarding each capsid: "the surprise is how much cargo these easily produced nanocontainers can carry." (Das et al, 2021 - illustrated).

\footnotetext{
24 -Kinesins: Sahoo et al (2018), Kanai et al (2004), and Salogiannis et al (2017); which are the "walk-motors" of ... -Axon-Transport: Griffin et al (1976), Brown et al (2005); Wang \& Jung (2005); Roy (2014); Maday et al (2014, illustrated); Sahoo et al (2018, illustrated); Sleigh et al. (2019). - Also see various online animations.

${ }^{25}$ E.g. see the reports quoted in Traill $(2019, \S 5.3)$ about: •"granules ... 200 nm in diameter" (Kanai et al, 2004), and - "Arc capsids encapsulate both the Arc protein (maybe other proteins too?), its mRNA, and whatever mRNA [or tatRNA?] happened to be in the vicinity at the time of encapsulation." (Neuronicus 2018). And the emphasis on $m$ RNA is waning:

"The presence of diverse RNA species further expands granule diversity. Aside from $m R N A$, this indicates various noncoding RNAs, such as ribosomal RNA, micro-RNA, and long noncoding RNA...." (Moujaber \& Stochaj, 2018). Thus closer investigation might perhaps find that some reported "mRNA" is actually taton-RNA (i.e. "ncRNA" dedicated to action-coding (hence schemoid-building), and maybe better labelled as "tatRNA" or "actRNA"). But of course that remains to be seen.
} 
(ii) The $20-40 \mathrm{~cm} /$ day could be fast enough to match with observed speeds of relocation to LTM at cortical sites. - Some further time-checking could be useful, but I'll not attempt it here.

This axon-transport method then is a serious contender for "letter-or-component" delivery. However we need to explain how such cargo is offloaded at the far end of its journey (via growthcones perhaps?), and installed within the cortex.

Another complication is: How are we to interpret neuro-journeys $\bullet$ which first go elsewhere (notably to the thalamus), or $\bullet$ duplicate pathways via different routes? - See the green part of Fig.(iv).- (Griffin, A. L. (2015)., Dolleman-Van der Weel, et al. (2019), Mathiasen, (2019), Schlecht et al., (2021)). - See the green part of Fig.(iv).

\subsubsection{Pros \& Cons of such Transport by Glia-or-Axons}

Such distinct pathways are just right if the intended destination is fixed and definite. That may often be true (especially for case $(\boldsymbol{a})$ ), but what if these "mail-items" have to be -sorted according to some criteria after the main journey, or indeed -distributed to "all interested parties"? Until we know better, it is probably wise to keep an eye on all such possibilities.

Earlier (in $\$ 3.6$ and $\S 4.5 .1(4)$ ) we encountered this same dilemma with the better-known (but less tangible) "phone-messages" in nerve-fibres. There any [A]-spike signals would necessarily be delivered to definite synapse sites. Meanwhile any [R]signals, following optics-principles, would have limited freedom to spread out from the ends of its nerve-fibre (acting as a radio-antenna), thus allowing for WiFi-like effects.

In contrast, our more tangible "parcels" of schemoids (with or without capsid packaging) could not have the benefit of WiFi wizardry. They might not need such further selective distribution; but if they do, they would seem to need (1) some form of "labels or addresses" to identify their correct destination, and (2) "ferries on a broad river" (not railways) as flexible transport - which leads us to:

5.4.4 Case $(f)$ - Capsids via the Bloodstream!

Consider the logical possibility of schemoidstructures being carried by the bloodstream! That is actually not as oddball as it sounds, given that blood serum is already known to carry quite an assortment of bio-molecules and structures, notably including RNAs (Umu et al., 2018; Hoban et al., 2018) - and including many other agents, e.g. "Bacteria can directly release factors into the systematic circulation or can translocate into blood"
(Logsdon et al., 2018). Also enzymes and other proteins (like $\operatorname{arc}$, used in some capsid-construction), neurotransmitters and short-chain fatty acids are other additions (ibid.).

The main obstacle is presumably the blood-brain barrier (BBB) which would now have to be crossed twice (ibid.; and Banks 2012). But there are various recognised methods for such crossing. ${ }^{26}$ Thus (e.g.): "steroid hormones ... by ...diffusion... whereas thyroid hormones and many peptides and regulatory proteins cross using transporters" (Banks 2012).

And note this title "Delivering genes across the blood-brain barrier: LY6A, a novel cellular receptor for AAV-PHP.B capsids" (Huang et al., 2019) - given that capsids (of some sort) are indeed what the present neo-Piagetian theory envisages.

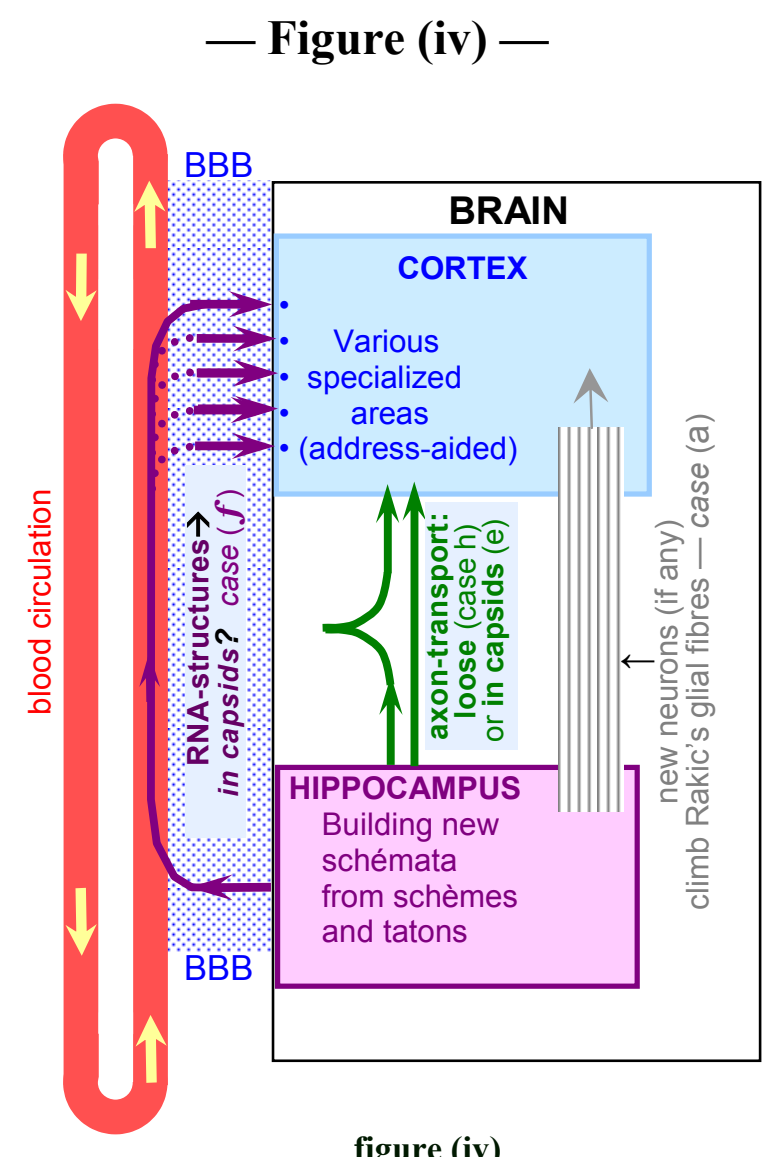

Postulated "postal services" carrying ncRNA schemoid concepts from the hippocampus for delivery into appropriate parts of the cortex:

(a) by Rakic's glial fibres (inside new neurons);

(e) by CNS axon transport of capsid-containers, perhaps directly or via the thalamus or suchlike;

(h) likewise, but with schemoids loose, lacking any enclosing capsid containers;

(f) via the bloodstream despite the BBBarrier, thereby offering the schemoid "parcels" to all sites, though maybe requiring a matching address.

\footnotetext{
${ }^{26}$ Lathe \& St.Clair $(2020, \S 5)$ list: • Active transport; -Migrating host-cells; $\bullet$ Direct neuronal; $\bullet$ Circumventricular. 
Likely Advantages of this "blood-postage": -Speed perhaps (despite the long repeated hit-ormiss detours via the heart! $\left.!^{27}\right)$. $\cdot$ Freedom from the strict guided allocation to specific cortical columns (perhaps a freedom required for $\mathrm{M}^{3} \mathrm{~L}, \mathrm{M}^{2} \mathrm{~L}$, and maybe even $\mathrm{M}^{1} \mathrm{~L}$ - hence the correlation with mode-change for human adulthood). This freedom should also allow the "postal round" to offer messages to all "interested" sites, wherever their location, thus permitting multiple "campuses" for the one topic (or for several related topics); — or to cope with disorganization caused by damage. ${ }^{12}$

-As a fortuitous aid in our lab-research: Experimental investigation should be a lot easier (and vastly less intrusive) if key traces are in the blood of humans and dolphins.

Likely Disadvantages of Blood-route, $(f)$ : -Destination-sites are no longer predetermined by Rakic's threads, nor by dedicated axons, hence a need for developing coded addresses \&/or descriptions for target sites. But it was argued above in $\S 3.6$ that such codes (as IR call-signs) are needed anyhow for any higher-intelligence - so we might expect the two systems (molecular label-code and "phone number") to fit together like "lock and key," as already considered.

-As noted already, such items would have to cross blood-brain barriers (BBB) twice:- once on leaving the hippocampus, and again on reaching likely target areas. It is far from obvious whether this is possible, but it seems to be a reasonable working hypothesis.

\subsection{Mixed routes for Schemoids into the Cortex?}

Does nature really need to choose between such strategies? If they are all truly feasible, and of comparable efficiency, then it seems reasonable to expect they will all occur at one time or another in this species or that - and perhaps to serve one special situation or another. In practice they probably would not all actually operate simultaneously, but there seems no compelling reason to stop that if the need arose.

\footnotetext{
${ }^{27}$ An ironic touch that! - bearing in mind the history of belief that the heart (and not the brain) is the centre of mental activity! (Cobb, 2020).
}

Note their likely specialities: • Case (a) would be an opportunistic mere "add-on" to the more fundamental task of constructing the cortex architecture as predetermined 2D layers of new neurons (with $x, y$ coordinates); - each layer follow in a choreographed sequence thus obtaining a predetermined $x, y, z$ matrix - according to the "Radial Unit Hypothesis" (Rakic, 2007). Even if one has reservations about such claimed-neatness, that $3 \mathrm{D}$ cortex matrix is likely to mainly embody inherited species-based start-up wisdom (like a computer's operating-system, or Kant's "a-priori" as discussed above in §3.5). Hence any newly-acquired information from outside might be somewhat out of place, and more suited to the other alternatives:

The axon-transport in - Cases ( $\boldsymbol{e}$ or $\boldsymbol{h}$ ), would deliver the "parcels" along fairly rigid routes dedicated axons, as discussed in \$5.4.3 above; (Jin \& Maren, 2015; Sigurdsson \& Duvarci, 2016; and Kanai et al, 2004). For many purposes that would doubtless suit very well, especially as any accompanying "phone-messages" could use the same axon for its [A]-spikes, \&/or its [R]-photonsof-IR. That could be exactly what is needed for routine archiving-tasks, (or sub-tasks supporting more sophisticated activities). Maybe time will tell.

It is less clear what to make fibres which first visit the thalamus en route (or to some other centre, as indicated by the kink in one of the green lines). But it seems likely that these offer some other service or variation. (Preston \& Eichenbaum, 2013; Dolleman-Van der Weel et al, 2019; Griffin, 2015; Mathiasen et al, 2019; and Schlecht et al, 2021). Meanwhile:

The Blood-transport of - Case ( $f$ ), could (if it exists) be much more flexible - delivering the same "message / model / algorithm / app" schemoids to all "departments" concerned with that particular topic; — or seeking out "working parties" whose addresses are unknown.

Until we know better, it might be prudent to assume provisionally that these four different modes respectively constitute $\mathrm{A} \%, \mathrm{E} \%, \mathrm{H} \%$ and $\mathrm{F} \%$ of any given activity within a given situation; - and we should try to evaluate those variables (bearing in mind that their associated phenomena could well be cooperating). Then if some-or-all of them turn out to be zero? ... Well, so be it! But we should probably keep looking for other feasible routes-andstrategies anyhow. 


\subsection{An Enhanced Respect for the Axon?}

Of course bio-scientists have long known that axons carry messages; and mostly they have assumed that those measurable $\bullet$ millisecond voltagespikes must be the only carriers of such messages. That $[\mathrm{A}]$-system is indeed one such method, but its uniqueness is here called into question.

There is now plausible experimental (Sun et al 2010; Zangari et al, 2021) and theoretical evidence (Traill 1978, 1988; Zangari et al, 2018) that myelinated axons can also act as coaxial cables carrying - "ultraweak photon emissions" (UPEs) of infra-red or other nearby wavelengths - offering a medium for any digitally-encoded messages needing transmission - the loosely affirmed [R] System.

These two methods ([A] \& [R]) are roughly analogous respectively to (i) simple analogue telephones, and (ii) digital emails; — both being very fast. But now there is also a third plausible method, even if it is less rapid: •axon-transport of "written-down" code - analogous to (iii) letterdelivery (suitable for large documents), even if nonaxon alternatives are also valid in some circumstances.

In sum, this looks as though evolution may have devised a sophisticated tri-modal master system for its messaging role. In retrospect, we should not be surprised: Brain operation, maintenance, construction and design are very demanding requirements, so why not co-opt every available tool for the purpose - and devise ways of getting them to cooperate?

This present project has concentrated on explaining human advanced intelligence (logicoriented) - calling for certain design-specifications. But the brain has many other tasks such as local navigation (Nadasdy et al 2022), or motor skills; and we should expect that they may need to configure the tri-modal system in different ways to meet their specific requirements (probably using different brainstem and cortex areas). Those other possibilities have not been explored here - but the versatile threefold messaging of the axon is likely to be involved in most of them. And of course it has other (mRNA \& nutrients etc.) supply capabilities as well.

\section{Part C-Application: Seeking to explain Gut-influence on Intelligence}

\section{Gut and its Surprises}

We would hardly expect the brain and gut to have any significant direct connection. They seem to have $\cdot$ unrelated roles to play, and they are $\cdot$ some $40 \mathrm{~cm}$ apart (in human adults) - with $\bullet$ no obvious special connection between them. And yet:-

\subsection{Intelligence etc. suffers if gut is Germ-Free!}

This surprise finding of intelligence-cognitivememory deficit is now well established! It is supported (e.g.) by studies where mice etc. were bred in a germ-free (GF) environment, and compared to controls - or to their own ability after becoming "normally infected" or fed with probiotics: (Gareau et al., 2011, Cryan \& Dinan 2012 (pp.5,6,8), Hoban et al., 2018 (fear-recall), Bastiaanssen et al., 2019 (p44)).

More serious are findings that depletion-of-gutbiome can promote actual pathologies:

Schizophrenia (Dinan et al., 2014); or also, Autism, Obesity, Stress, Multiple sclerosis, Alzheimer's and Parkinson's Diseases, ${ }^{28}$ (Bastiaanssen et al., 2019). Although these latter effects are less related to our present "intelligence" topic, they involve a significant logistical background which needs examination in the next section, before returning to "intelligence-proper" in $\S 6.3$.

\subsection{Existing Part-Explanations for "Gut-Brain"}

(i) The gut obviously harbours bacteria; and as noted in $\$ 5.4 .4$, Logsdon et al (2018) report that "Bacteria can directly release factors into the systemic circulation or can translate into blood." And they add that bacteria "can alter peripheral immune cells to promote interactions with the $B B B \ldots$. [My italics in both cases]

In particular they suggest that gut microbes may have their affect... by:

\footnotetext{
${ }^{28}$ Plus ADHD, Bipolar, Major Depression, MS, Anxiety, OCD, and Eating Disorders (pp. 43-44).
} 
$\alpha \cdot$ reprogramming immune cells,

$\beta \bullet$ cytokine secretions,

$\gamma \bullet$ manufacturing bacteriophages,

$\boldsymbol{\delta} \bullet$ translocating into the systematic circulation, and $\boldsymbol{\varepsilon} \bullet$ (sometimes) moving [themselves] across the BBB.

(ii) Meanwhile Hoyles et al (2018) offer a similar list (with some overlap) as: "Three recognised mechanisms exist by which the microbiome influences the gut-brain axis:"

1 Changing autonomic/sensorimotor connections,

2 immune activation, and

3- neuroendocrine; - to which they ADD:

4. gut-metabolites produce changes in the BBB.

- These are all reasonable suggestions, and probably often interacting, but we might well expect more. Thus note some unaddressed issues which test their scope:

(a) As yet, there seems no reliable indication as to whether such effects will improve or damage performance in any given case. I.e. such accounts are somewhat vague at this stage. "Damage" seems the more likely - and that is consistent with the long list of pathologies offered above by

Bastiaanssen et al (2018).

(b) These mostly seem associated with whatever the relevant agent's average local concentration may be. They would thus resemble the "analogue" variables encountered in $\$ 2.1$ above - suitable as regulators such as "volume control" (intentional or otherwise).

But $\$ 6.1$ (above) was concerned with the improvements in intelligence and cognition arising from diversity in the gut microbiome - and those would seem to require digital capabilities. So perhaps we should look further:-

\subsection{How could gut-diversity raise intelligence?}

Let us add another suggestion to the latter list of possible mechanisms for gut influence:-

5 gut may well supply extra "useful junk",29 as candidate-coding for would-be tatons in the hippocampus - IF that "junk" can get there!

Once in the hippocampus, such arbitrary RNAcode could well augment the pool of pre-coded "default-or-junk text" postulated to exist as part of the inherited genome ( $\$ 3.2$ above).

Arguably the advantage of this arrangement would be to increase the local biodiversity - to facilitate the building of never-foreseen conceptual schéma structures on an enhanced scale - hence extra inventiveness. (Also note the parallel to

\footnotetext{
${ }^{29}$ See $\$ 3.2$ above. Thereby giving a better range of choices.
}

bacteria exchanging their own genetic material as a strategy for faster evolution).

Metaphorically then: If indeed the inherited "blank taton-prototypes" ( $\$ 3.2$ above) do serve as "oddments in a handyman's workshop" then by extension, the GUT's microbiome may serve as the local "garbage tip" which occasionally offers useful especially-unforeseen pickings for those who dare to look! - Potentially useful "junk" in both cases, but with different degrees of familiarity-vs-novelty. And note (for both) the parallel with the arbitrary "objet trouvé" concept for extreme a-priori material (Traill, 1999, Ch.4).

Thus this extra gut-biome source offers an alternative pool of arbitrary junk for hippocampal (etc?) processing, and hence different clinical biases: e.g. "Fecal Microbiota Transplantation (FMT)" (Bastiaanssen et al, 2019, p41; Cryan \& Dinan, 2012, pp5-6). But then:-

\subsection{How could such pre-coding reach the hippocampus?}

(a) Using axon-transport via the Vagus Nerve? (Forsythe et al., 2014; Suarez et al, 2018).

This seems the most suitable method because: -Anatomically it is the most direct and salient pathway. $\cdot$ It is now well established that RNA can travel such axonal routes (see $\S 5$ above).

- The method would probably apply whether or not the RNA fragments were loose or in capsids; and -it would not waste resources spreading the finds to irrelevant sites.

(b) Via the bloodstream? That did make sense (above) for assembled schemoids supposedly broadcast to multiple sites in the cortex; however here that seems unnecessary - and rashly hazardous (encouraging random "junk" into the blood).

Moreover it would have BBB and other barriers to negotiate with a new set of parameters to be evolved and maintained.

In short this mode seems very unlikely, though it is perhaps appropriate to keep it in mind as a vague possibility - in which case information about barriers (Banks 2012; p.4111-2), pore-sizes (Robinson \& Rapoport, 1987), and capsid-sizes ${ }^{30}$ might become more relevant.

\footnotetext{
${ }^{30}$ (Goldsmith et al., 2004). Also "The herpesvirus virion is genetically and structurally one of the largest and most complex viruses known. It has a ...capsid with a diameter of $125 \mathrm{~nm}$ " (Yuan et al., 2018) — this figure was used in the calculations of schemoid-logistics (Traill, 2019).
} 


\section{In Conclusion}

(1) Some mental abnormalities seem likely to be explicable via this overall model, e.g.: (a) the $\S 4.2$ idea of ultramicro-"switches" (within each taton) may be one important physical mechanism giving effect to chemical agents like drugs and hormones - or Freudian concepts like repression. (b) Abnormalities in the permeability of the BBB (in the hippocampus \&/or the cortex (§5)) may help account for dementia symptoms of various types. (c) In principle, simple genetic mental traits and mannerism are easily explained as "a-priori" ncRNA-coding. (d) Hence maybe such a coding lack-or-eccentricity is also a leading factor in more major conditions like autism.

(2) New experimental approaches are suggested by such new theoretical models, even if those theories are not entirely correct in themselves. In particular, who would have otherwise thought to imagine that RNA-sampling from blood could perhaps be a useful non-invasive strategy for investigating details of advanced thought?

(Fig. (iv)).

(3) This is also a case-study for the potential power of theoretical detective-work in the right interdisciplinary circumstances. ${ }^{31}$ Such theory was rather deprecated throughout the 1900s, thanks to the naïve "Logical Positivist" perfectionism of Mach (1905), Carnap (1928), and others - at least until Ayer (1978) admitted their error on TV. Of course any hypothesis can be wrong and lead to a dead-end; but if (for example) one's structural Hypothesis-A leads to a surprising Hypothesis-B, which incorporates $\mathrm{C}$, and then keeps progressing constructively through $\mathrm{D}, \mathrm{E}$, and $\mathrm{F}$, then perhaps it should at least be taken seriously — as Whewell (1847) pointed out long ago.

More formal recent supports for theory include: Quine (1951), Cushan (1983), Creath (1991), and Putnam (2004). In fact they have shown that a metahypothesis like Mach-derived Logical-Positivistic methodology can itself be wrong and misleading, especially if taken too literally or applied to the wrong sort of problem (like using a simple $\mathrm{M}^{\text {low }} \mathrm{L}$ Popperian strategy, to investigate complex $\mathrm{M}^{\text {high }} \mathrm{L}$ type systems).

Of course experimental-or-clinical testing is still vitally important - when feasible, and in its proper

\footnotetext{
${ }^{31}$ For another case-study (involving theories of insectnavigation), see the critique of that conflict (Traill 2005c). Also another discussion of the role for theory is given in Traill (2010a; Appendix B).
}

place. But a major trap for the unwary is that we can all-too-easily focus on salient phenomena (which may be only incidental or secondary), like foulsmelling "miasmas" as the supposed cause of disease, thus delaying us historically from even considering the possibility of hidden bacterial infection, which was only then demonstrated by Pasteur. And, giving Piaget (1927) the last word: Young children often have difficulty seeing how the invisible insubstantial wind could cause trees to move - assuming instead that the salient "humanlike" trees are causing the wind!

\section{ACKNOWLEDGEMENT}

I wish to thank Sherrill Hallmond for useful discussion and valuable suggestions for wider extension.

\section{References}

Ashby W.R. (1960: $2^{\text {nd }}$ edition). Design for a Brain. Chapman \& Hall: London.

Ayer A.J. (1978). "On the cleansing of the metaphysical stables". The Listener, 99(2549), 268-270.

[Originally broadcast under the title "Logical Positivism and its Legacy", BBC-2].

Badre D, A.S.Kayser, \& M.D'Esposito (2010)

"Frontal cortex and the discovery of abstract action rules" Neuron. 2010 Apr 29; 66(2): 315-326.

https://doi.org/10.1016/j.neuron.2010.03.025

Banks W.A. (2012 Sep). "Brain meets body: the blood-brain barrier as an endocrine interface" Endocrinology, 153(9): 4111-4119. https://doi.org/10.1210/en.2012-1435

Bannister Don. (1968). "The Myth of Physiological Psychology" Bulletin of the British Psychological Society, 21(73), 229-231.

Barrett L.W., S.Fletcher \& S.D.Wilton, (2012 April 27). "Regulation of eukaryotic gene expression by the untranslated gene regions and other non-coding elements". Cellular and Molecular Life Sciences. 69 (21): 3613-3634. https://doi.org/10.1007/s00018-012-0990-9 PMC 3474909. PMID 22538991

Bastiaanssen T.F.S., S.M.Cowan, M.J.Claesson, T.G.Dinan \& J.F.Cryan (2019 Jan 1). "Making Sense of ... the Microbiome in Psychiatry" Int.J.Neuropharmacology, 22(1): 37-52. https://doi.org/10.1093/ijnp/pyy067

Becker L.A. \& A.D. Gitler (2015-8-5) “ $\{$ RNA and Protein $\}$ Granules: It's all starting to come together". eLife. https://doi.org/10.7554/eLife.09853

Beth E.W. \& J.Piaget (1961). Épistémologie mathématique et psychologie: Essai sur les relations entre la logique formelle et la pensée réelle. I (1966) Mathematical Epistemology and Psychology. Dordrecht: D. Reidel

Božič A.L., A.Šiber, \& R.Podgornik (2013). "Statistical analysis of sizes and shapes of virus capsids and their resulting elastic properties". J.Biol.Phys., 39(2): 215-228. https://doi.org/10.1007/s10867-013-9302-3

Brette R. (2017 Jul. 27 first posted online) "Is coding a relevant metaphor for the brain?" bioRxiv http://dx.doi.org/10.1101/168237. 
Brown A, I.Wang, \& P.Jung (2005) 'Stochastic simulation of neurofilament transport in axons: the "stop-and-go" hypothesis'. Mol.Biol.Cell 16(9), 4243-4255. https://doi.org/10.1091/mbc.E05-02-0141

Carnap R. (1928/1967). The Logical Structure of the World [and Pseudoproblems in Philosophy].

Routledge \& Kegan Paul

Chamberlain J.W., G.W.Chantry, H.A.Gebbie, N.W.B.Stone, T.B.Taylor, and G.Wyllie. (1966 May 21). "Submillimetre absorption and dispersion of liquid water". Nature, London, 210, 790-791. https://doi.org/10.1038/210790a0

Cifra M, \& P.Pospíšil (2014) "Ultra-weak photon emission from biological samples: definition, mechanisms, properties, detection and applications." Journal of Photochemistry and Photobiology B: Biology. 139: 2-10. https://doi.org/10.1016/j.jphotobiol.2014.02.009

Cifra M, C.Brouder, M.Nerudová, \& O.Kučera (2015 Feb 25) "Biophotons, coherence and photocount statistics: a critical review". arXiv: 1502.07316v1 / J.Luminescence, 164. https://doi.org/10.1016/j.jlumin.2015.03.020

Clark Andy (2013 May 10). "Whatever next? Predictive brains, situated agents, and the future of cognitive science" Behavioral and Brain Sciences. 36(3), 1-73 https://doi.org/10.1017/S0140525X12000477

Cobb M. (2020, Mar.12). The idea of the brain: a history. Profile Books.

Commons M.L., E.A.Goodheart, A.Pekker, T.L.Dawson, K.Draney, \& K.M.Adams. (2008). Using Rasch scaled stage scores to validate orders of hierarchical complexity of balance beam task sequences. J Appl Meas. 2008; 9(2):182199. PMID: 18480514.

Creath R (1991/2015, ed) Dear Carnap, dear Van: The QuineCarnap correspondence and related work. University of California Press. ISBN 0520909828.

Cryan J.F. \& T.G.Dinan (2012 Sep 12). "Mind-altering microorganisms: the impact of the gut microbiota on brain and behaviour" Nature Reviews Neuroscience. https://doi.org/10.1038/nrn3346

Cushan A-M. (1983/2014). Investigations into Facts and Values - Groundwork for a theory of moral conflict resolution. Thesis, Melbourne University, and Ondwelle: Melbourne.

https://www.ondwelle.com/ValueJudgements.pdf

Das S, M-K.Yau, J.Noble, L.dePascalis, \& M.G.Finn (2021). "Transport of molecular cargo by interaction with virus-like particle RNA". Angewandte Chemie. 61(2), e202111687 https://doi.org/10.1002/anie.202111687

Deitsch J.S., and G.A.Banker (1993). "An Electron Microscopic Analysis of Hippocampal Neurons Developing in Culture: Early stage in the emergence of polarity". J.Neurosci. 13(10), 4301-4316 https://doi.org/10.1523/JNEUROSCI.13-1004301.1993

Dinan T.G., Y.E.Borre \& J.F.Cryan (2014). "Genomic of schizophrenia: time to consider the gut microbiome". Molecular Psychiatry, 19, 1252-1257. https://doi.org/10.1038/mp.2014.93

Dolleman-Van der Weel, M.J., A.L.Griffin, H.T.Ito, M.L.Shapiro, M.P.Witter, R.P.Vertes, \& T.A.Allen (2019). "The nucleus reuniens of the thalamus sits at the nexus of a hippocampus and medial prefrontal cortex circuit enabling memory and behavior." Learning \& Memory, 26(7), 191205. https://doi.org/10.1101/1m.048389.118

Elvira G, S.Wasiak, V.Blandford, et 11 al (2006) Characterization of an RNA Granule from Developing Brain. Molecular \& Cellular Proteomics. 5.4, 635-651. https://doi.org/10.1074/mcp.M500255-MCP200
Fodor J.A. (1975). The Language of Thought. Crowell ISBN 0-690-00802-3

Fodor J.A. (2008). The Language of Thought Revisited. Oxford University Press. ISBN 0199548773

Forsythe P, J.Bienenstock J, WA.Kunze (2014) "Vagal Pathways for Microbiome-Brain-Gut Axis Communication" Adv Exp Med Biol. 817: 115-33. In AEMB Book Series, vol.817. [First Online: 09 June 2014] PMID: 24997031 https://doi.org/10.1007/978-1-4939-0897-4 5

Fraser A, and A.H.Frey. (1968). "Electromagnetic emission at micron wavelengths from active nerves". Biophys.J., 8(6), 731-734. https://doi.org/10.1016/S0006-3495(68)86517-8 PMID: 5699805

Fuster J.M. \& Bressler S.L. (2012 Apr, (Epub:Mar 20)) “Cognit activation: a mechanism enabling temporal integration in working memory." Trends Cogn Sci.; 16(4): 207-18. https://doi.org/10.1016/j.tics.2012.03.005

Gallistel C.R. \& P.D.Balsam (2014 Feb) "Time to rethink the neural mechanisms of learning and memory" Neurobiol.Learn.Mem. 108, 136-144.' PMID: 24309167 https://doi.org/10.1016/j.nlm.2013.11.019

Gareau M.G., E.Wine, D.M.Rodrigues, J.H.Cho, M.T.Whary, D.J.Philpott, G.Macqueen, \& P.M.Sherman (2011 Mar).

"Bacterial infection causes stress-induced memory dysfunction in Mice" Gut, 60(3), 307-317. https://doi.org/10.1136/gut.2009.2009.202515 Epub 2010 Oct 21

Goldsmith C.S., K.M.Tatti, et 8 al. (2004 Feb.) "Ultrastructural Characterization of SARS Coronavirus". Emerging Infectious Diseases. 10(2), 320-325.

Griffin A.L. (2015). "Role of the thalamic nucleus reuniens in mediating interactions between the hippocampus and medial prefrontal cortex during spatial working memory." Frontiers in Systems Neuroscience, 9. https://doi.org/10.3389/fnsys.2015.00029

Griffin J.W., D.L.Price, D.B.Drachman, and W.K.Engel, (1976). Axonal transport to and from the motor nerve ending. Ann. N Y Acad. Sci. 274, 31-45. PMID: 60895 https://doi.org/10.1111/j.1749-6632.1976.tb47674.x

Gurwitsch A. (1924a) „Physikalisches über mitogenetische Strahlen“. Archiv für Entwicklungsmechanik, 103: 490-498. https://doi.org/10.1007/BF02107498

Gurwitsch A. (1924b). Les problèmes de la mitose et les rayons mitogénétiques. Bull. d. Histol. Appl.,1: 486

Hamaker J.P., J.D.O'Sullivan, \& J.E.Noordam (1977). "Image Sharpness, Fourier Optics, and Redundant Spacing Interferometry", J. Opt. Soc. Am., 67, 1122-1123. https://doi.org/10.1364/JOSA.67.001122

Hebb D.O. (1949/1964). The Organization of Behaviour. Wiley: New York \& London

Hempel Carl G. (1965) "Studies in the logic of confirmation". (3) in Hempel, Carl G. Aspects of Scientific Explanation and Other Essays in the Philosophy of Science. New York.

Hoban A.E., R.M.Stilling, G.Moloney, F.Shanahan, T.G.Dinan, G,Clarke and J.F.Cryan (2018). "The microbiome regulates amygdala-dependent fear recall” Molecular Psychiatry, 23, 1134-1144. https://doi.org/10.1038/mp.2017.100

Horgan John (2016, Mar. 22) "The Singularity and the Neural Code." Sci.Amer.: Cross-Check Blog.

Hoyles L, T.Snelling, U-K.Umlai. J.K.Nicholson, S.R.Carding, R.C.Glen \& S.McArthur (2018). "Microbiome-host systems interactions: protective effects of propionate upon the bloodbrain barrier". Microbiome, 6 : 55 . https://doi.org/10.1186/s40168-018-0439-y 
Huang Q, K.Y.Chan, et 8 al.+ B.E.Deverman (2019 Nov 14). "Delivering genes across the blood-brain barrier: LY6A, a novel cellular receptor for AAV-PHP.B capsids" Plos One. https://doi.org/10.1371/journal.pone.0225206

Hume David (1777/1999). An enquiry concerning human understanding. Oxford University Press

Hydén H. (1967b). "Biochemical changes accompanying learning”. In G.C.Quarton, T.Melnachuk, and F.O.Schmitt (eds), The Neurosciences, pp.765-771, 913, 914. Rockefeller University Press.

Hyland M.E. (1977). On the Nature and Use of Hypothetical Constructs: Rules for theory composition.

School of Behavioural and Social Sciences, Plymouth Polytechnic.

Hyland M.E. (1981). Introduction to Theoretical Psychology. Macmillan: London. ISBN 0-333-25827-4

Jayachandran M., S.B.Linley, M.Schlecht, S.V.Mahler, , R.P.Vertes, \& T.A.Allen, (2019). Prefrontal pathways provide top-down control of memory for sequences of events. Cell Reports, 28(3), 640-654.e6. https://doi.org/10.1016/j.celrep.2019.06.053

Jerne H.K. (1955 Nov 15) "Natural-selection Theory of Antibody formation" PNAS, 41 (11): 849-857. https://doi.org/10.1073/pnas.41.11.849

Jerne H.K. (1966) “Antibody formation and immunological memory” In Gaito, J. (1966a) Macromolecules and Behavior. Meredith/Appleton-Century-Crofts: New York; Ch.9, pp151-157

Jin J, \& S.Maren (2015). Prefrontal-hippocampal interactions in memory and emotion. Frontiers in Systems Neuroscience, 9. https://doi.org/10.3389/fnsys.2015.00170

Kanai Y, N.Dohmae, \& N.Hirokawa (2004-8-19) Kinesin Transports RNA: isolation and characterization of an RNAtransporting granule. Neuron. 43(4), 513-525. https://doi.org/10.1016/j.neuron.2004.07.022

Kant I. (1787/1855) (Transl. JMD.Meiklejohn, from $2^{\text {nd }}$ edition) Kritik der reinen Vernunft / Critique of Pure Reason. Dent

Koch Ch. \& G.Marcus (2014 June 17). "Cracking the brain's codes." MIT Technology Review, 117(4), 42-46. https://nyuscholars.nyu.edu/en/publications/cracking-the-brains$\underline{\text { codes }}$

Kolk S.M., \& P.Rakic (2022 / 2021) "Development of prefrontal cortex", Neuropharmacology, 47, 41-57. https://doi.org/10.1038/s41386-021-01137-9

Lacey B, (1966) A Dictionary of Philosophy. Routledge \& Kegan Paul, London.

Lakatos Imré. "Changes in the problem of inductive logic." in John Worrall \& Gregory Curry (Eds). Mathematics, Science \& Epistemology. Philosophical Papers, Vol 2. Cambridge University Press.

Lashley K.S., (1924) "Studies of cerebral functioning in learning. V. The retention of motor habits after destruction of the so-called motor areas in primates", Arch. Neurol. Psychiat., 12, 249-276. https://doi.org/10.1001/ARCHNEURPSYC.1924.02200030002001

Lashley K.S., (1929) Brain mechanisms and intelligence, University of Chicago Press.

Lathe R., and D.St.Clair (2020). "From conifers to cognition: Microbes, brain and behavior" Genes, Brain and Behavior, 19: e12680 https://doi.org/10.1111/gbb.12680

Lemos N. (2007). An introduction to the Theory of Knowledge. Cambridge University Press.
Logsdon A.F., M.A.Erickson, E.M.Rhea, T.S.Salameh \& W.A.Banks (2018). "Gut Reactions: How the blood-brain barrier connects the microbiome and the brain". Experimental Biology and Medicine, 243: 159-165. https://doi.org/10.1177/1535370217743766

Mach Ernst (1905/1976) Erkenntnis und Irrtum. Skizzen zur Psychologie der Forschung / Knowledge \& Error. D.Reidel: Dordrecht

Maday S, A.E.Twelvetrees, A.J.Moughamian, \& E.L.F.Holzbaur (2014-10-22) . "Axonal transport: cargospecific mechanisms of motility and regulation".

Neuron. 84 (2): 292-309. PMID 25374356. PMC $\underline{4269290}$ https://doi.org/10.1016/j.neuron.2014.10.019

Malik R, Y.Li, S.Schamiloglu, \& V.S.Sohal (2021). Top-down control of hippocampal signal-to-noise by prefrontal longrange inhibition. BioRxiv, 2021.03.01.433441. https://doi.org/10.1101/2021.03.01.433441

Martin, C.R, V.Osadchiy, A.Kalani, \& E.A.Mayer (2018). "The Brain-Gut_Microbiome Axis". Cellular and Molecular Gastroenterology and Hepatology. 6(2). $\underline{\text { https://doi.org/10.1016/j.jcmgh.2018.04.003 }}$

Mathiasen M.L., E.Amin, A.J.D.Nelson, , C.M.Dillingham, S.M.O'Mara, \& J.P.Aggleton (2019). "Separate cortical and hippocampal cell populations target the rat nucleus reuniens and mammillary bodies."

The European Journal of Neuroscience, 49(12), 1649-1672. https://doi.org/10.1111/ejn.14341

Mattick J.S. (2001). "Noncoding RNAs: the architects of eukaryotic complexity". EMBO Reports 2(11), 986-991. http://emboreports.npgjournals.com/cgi/content/full/2/11/986

Mattick J.S. (2003). "Challenging the dogma: The hidden layer of non-protein-coding RNAs on complex organisms" Bioessays. 25, 930-939. www.imbjena.de/jcb/journal_club/mattick2003.pdf

Mattick J.S. (2004 Oct). "The hidden genetic program of complex organisms" Scientific American. 291(4), 30-37.

Merianda T.T., C.Gomes, et.al. \& J.L.Twiss (2013-8-21) Axonal localization of Neuritin/CPG15 mRNA in neuronal populations through distinct 5' and 3' UTR elements. J.Neurosci.33(34): 13735-13742.

https://www.ncbi.nlm.nih.gov/pmc/articlrs/PMC3755718/

Michelson A.M. \& S.H.Orkin, (1980-11-01). "The 3' untranslated regions of the duplicated human alpha-globin genes are unexpectedly divergent". Cell. 22 (2 Pt 2): 371377. doi: 10.1016/0092-8674(80)90347-5 PMID 7448866.

Monod J., \& F.Jacob (1961). "General conclusions: telenomic mechanisms in cellular metabolism, growth, and differentiation" Cold Spring Harbor Symposia on Quantitative Biology, 26, 389-401.

Moujaber O, \& U.Stochaj (2018-5-30). Cytoplasmic RNA Granules in somatic maintenance. Gerontology. 64: 485-494. https://doi.org/10.1159/000488759

Nadasdy Z., D.H.P.Howell, Á.Török, et 5 al (2022-5-4) Phase coding of spatial representations in the human entorhinal cortex. Science Advances, 8(18), eabm6081 https://doi.org/10.1126/sciadv.abm6081

Neuronicus (2018) in The Science Portal: https://scientiaportal.wordpress.com/2018/01/28/interviewwith-jason-d-shepherd-phd/

O'Sullivan J.D., G.R.Daniels, T.M.P.Percival, D.I.Ostry, \& D.Eastwood (1996, Jan.23). "Wireless LAN" [Local Area Network]. US Patent Number 5487069. [Assignee: CSIRO].

Parolisi R, B.Cozzi \& L.Bonfanti (2018 Jul.20) "Humans and Dolphins: Decline and Fall of Adult Neurogenesis" Frontiers in Neuroscience. 12, article 497. https://doi.org/10.3389/fnins.2018.00497 
Piaget J. (1927/1930) La causalite physique chez l'enfant / The child's conception of physical causality. Routledge \& Kegan Paul.

Piaget J. (1949). Traité de logique. Armand Collin: Paris. Republished (1972) as Essai de Logique Operatoire, Dunod

Piaget J. (1970a/1972) Psychology \& Epistemology: towards a theory of knowledge. Penguin.

Pinto-Teixeira F., C.Koo, A.M.Rossi, et al + A. Del-ValleRodriguez, C.Desplan (2018 Apr 5). "Development of concurrent retinotropic maps in the fly motion detection circuit. Cell 173(2), 485-498.E11.

https://doi.org/10.1016/j.cell.2018.02.053

Popper K.R. (1934) Logik der Forschung / The Logic of Scientific Discovery. Hutchinson

Popper K.R. (1975/1994) "The rationality of scientific revolutions"; (i) in Rom Harré (ed.) (1975) Problems of Scientific Revolution. Scientific Progress and Obstacles to Progress in the Sciences, The Herbert Spencer Lectures 1973. Clarendon Press

Preston A.R. \& H.Eichenbaum (2013). Interplay of hippocampus and prefrontal cortex in memory. Current Biology : CB, 23(17), R764-R773. https://doi.org/10.1016/j.cub.2013.05.041

Putnam H (2004) The collapse of the fact/value dichotomy and other essays. Harvard University Press. ISBN: 9780674013803.

Quine W.v.O. (1951), “Two Dogmas of Empiricism”, Philosophical Review, 60: 20-43; reprinted in From a Logical Point of View, pp. 20-46. https://doi.org/10.2307/2266637

Rakic P (1975) "Cell migration and neural ectopias in the brain" [conference] in: D.Bergma (ed,1982!) Birth Defects: Original Article Series. 11(7): 95-129. PMID: 813795

Rakic P (1978) "Neuronal migration and contact guidance in the primate telencephalon." Postgraduate Medical Journal. 54, Suppl 1, 25-40. PMID: 364453

Rakic P (1985). "Limits of neurogenesis in primates". Science, 227(4690), 1054-1056. [PubMed: 3291 116] https://doi.org/10.1126/science.3975601

Rakic P (1988). "Specification of cerebral cortical areas" Science 241, 170-176. [PubMed: 3291116] https://doi.org/10.1126/science.3291116

Rakic P (1998) "Images in neuroscience. Brain development, VI: radial migration and cortical evolution." American Journal of Psychiatry. 155(9): 1150-1151. https://doi.org/10.1176/AJP.155.9.1150

Rakic P (2007 Oct 1). "The radial edifice of cortical architecture: from neuronal silhouettes to genetic engineering." Brain Res. Rev. 55(2), 204-219. https://doi.org/10.1016/j.brainresrev.2007.02.010

Ray P.S. (1972). "Broadband complex refractive indices of ice and water". Appl. Optics, 11(8), 1836-1844.

PMID: 20119241; https://doi.org/10.1364/AO.11.001836

Reed J.C., N.Westergreen, et 6 al., (2018-5), Formation \{of RNA Granule-Derived Capsid Assembly intermediates appears to be conserved between Human Immunodeficiency Virus type 1 and the nonprimate lentivirus Feline Immunodeficiency Virus. J.Virology, 92(9), e01761-17. https://doi.org/10.1128/JVI.01761-17

Robertson C.W., B.Curnutte, \& D.Williams. (1973). "The infrared spectrum of water". Molecular Physics, 26(1), 183-191. [online 2006 Aug 23]. https://doi.org/10.1080/00268977300101501
Robinson P.J. and S.I.Rapoport (1987 Sep 01) "Size selectivity of blood-brain barrier permeability at various times after osmotic opening" Am.J.Physiology, 253(3) doi: 10.1152/ajpregu.1987.253.3.R459; PMID: 2443025

Rose S.P.R. (2015 Feb 14) "50 years of neuroscience". Lancet, 385(9968), 598-9.

https://doi.org/10.1016/S0140-6736(15)60224-0

Roy, S. (2014 Feb 1) "Seeing the unseen: the hidden world of slow axon transport" Neuroscientist 20(1), 71-81 https://ncbi.nlm.nih.gov/pmc/articles/PMC3902140/

Russell Bertrand. (1924) "Logical atomism.” In: Muirhead, J.H.(Ed.). Contemporary British Philosophy.

Allen \& Unwin

Sahoo P.K., D.S.Smith, N.Perrone-Bizzozero, \& J.L.Twiss (2018) Axonal mRNA transport and translation at a glance. J.Cell Sci., 131. https://doi.org/10.1242/jcs.196808

Salmon W.C. (1967) The Foundations of Scientific Inference. University of Pittsburgh Press.

Salogiannis J \& S.L.Reck-Peterson (2017-2) Hitchhiking: a non-canonical mode of microtubule-based transport. Trends in Cell Biology. 27(2), 141-150.

https://doi.org/10.1016/j.tcb.2016.09.005

Sankey H (2008). Scientific realism and the rationality of science. Ashgate: Aldershot ISBN 978-0-7546-5888-7

Schlecht M, M.Jayachandran , G.E.Rasch , \& T.A.Allen (202107-22) "Dual projecting cells linking thalamic and cortical communication routes between the medial prefrontal cortex and hippocampus"

$\underline{\text { https://doi.org/10.1101/2021.07.21.453279 }}$

Scoville W.B. \& B.Milner. (1957). Loss of recent memory after bilateral hippocampal lesions. Journal of Neurology,

Neurosurgery and Psychiatry. 20, 11-21. https://doi.org/10.1176/jnp.12.1.103 PMID: 10678523

Sigurdsson T \& S.Duvarci, (2016). Hippocampal-prefrontal interactions in cognition, behavior and psychiatric disease. Frontiers in Systems Neuroscience, 9. https://doi.org/10.3389/fnsys.2015.00190

Sleigh J.N., A.M.Rossor, A.D.Fellows, A.P.Tosolini, G.Schiavo (December 2019). "Axonal transport and neurological disease". Nat Rev Neurol. 15(12): 691-703. https://doi.org/10.1038/s41582-019-0257-2

Sorrells S.F., M.F.Paredes et 16 al + Arturo Alvarez-Buylla (2018 Mar 15). "Human hippocampal neurogenesis drops sharply in children to undetectable levels in adults." Nature 555, 377-381. https://doi.org/10.1038/nature25975

Sporns O., \& R.Kötter (2004-10-26) Motifs in Brain Networks. PLoS Biol, 2(11): e369. https://doi.org/10.1371/journal.pbio.0020369

Squire L.R., \& E.R.Kandel (1999). Memory: from mind to molecules. Scientific American Library: New York.

Steward O (1997 Jan) mRNA Localization in Neurons: A multipurpose mechanism? Neuron. 18, 9-12. https://doi.org/10.1016/s0896-6273(01)80041-6

Suarez A.N., T.M. Hsu, C.M.Liu, et 5 al, \& S.E.Kanoski (2018-6-5). Gut vagal sensory signaling regulates hippocampus function through multi-order pathways. Nature Communications. https://doi.org/10.1038/s41467-018$\underline{04639-1}$

Sun Y[an], Chao Wang, \& Jiapei Dai (2010, Jan). "Biophotons as neural communication signals demonstrated by in situ biophoton autography". Photochem. Photobiol. Sci., 9, 315-322 https://doi.org/10.1039/b9pp00125e 
Traill R.R. (1976a /2007). The gulf between behavioural psychology and fundamental physiology: a systematic attempt to bridge the gap. Monograph 15, Institute of Cybernetics, Brunel University. https://www.ondwelle.com/OSM05.pdf

Traill R.R. (1976c /2007c:oct). Short papers and letters on the 'linear micro-element' theory of mental mechanism; and related questions of scientific method.

Monograph 18, Cybernetics, Brunel University. https://bura.brunel.ac.uk/handle/2438/727/1/BrMon18h.pdf . or www.ondwelle.com/OSM06.pdf

Traill R.R. (1978/2006). Molecular explanation for intelligence..., Thesis, Brunel University; ( in 2 files: Part-B [technical $]+$ all other parts incl. A \& C) https://bura.brunel.ac.uk/handle/2438/729

Traill R.R. (1988). "The case that mammalian intelligence is based on sub-molecular memory coding and fibre-optic capabilities of myelinated nerve axons". Speculations in Science and Technology. 11(3), 173-181. www.ondwelle.com/OSM10en.pdf

Traill R.R. (1999). Mind and Micro-Mechanism: a hunt for the missing theory. Ondwelle:Melbourne ISBN: 0-9577737-0-6 (p.bck) https://www.ondwelle.com/BK0 MU6.PDF

Traill R.R. (2000). Physics and Philosophy of the Mind. Ondwelle: Melbourne. ISBN: 0-9577737-1-4 (p.bck) http://www.ondwelle.com/BK1 V28.PDF

Traill R.R. (2005a). Strange regularities in the geometry of myelin nerve-insulation - a possible single cause. Ondwelle: Melbourne. www.ondwelle.com/OSM01.pdf - Also in Gen.Sci.J. www.wbabin.net/physics/traill4.pdf

Traill R.R. (2005c). How Popperian positivism killed a goodbut-poorly-presented theory - Insect Communication by Infrared. Ondwelle: Melbourne.

https://www.ondwelle.com/OSM03.pdf;

Also in Gen.Sci.J. www.wbabin.net/physics/traill7.pdf

Traill R.R. (2008/2005b). Thinking by Molecule, Synapse, or both? - From Piaget's schema, to the Selecting/Editing of $n c R N A$. Ondwelle.* www.ondwelle.com/OSM02.pdf French version*: https://www.ondwelle.com/FrSM02.pdf German version: https://www.ondwelle.com/OSM02de.pdf

* also in Gen.Sci.J.;

Traill R.R. (2010a Oct). Meaningful UV and IR photonexchange within bio-tissue? - Interdisciplinary evidence, and a new way to view asbestos toxicity. Ondwelle: Melbourne. https://www.ondwelle.com/UV1_evidence.pdf also in General Science Journal.

Traill R.R. (2010b Nov). "The theoretical case that some asbestos fibres could trigger cancer optically, while others act mechanically". Ondwelle Publications: Melbourne. http://www.ondwelle.com/UV2 trigger.pdf also in General Science Journal.

Traill R.R. (2011) "Coherent Infra-Red as logically necessary to explain Piagetian psychology and neuro-microanatomy Two independent corroborations for Gurwitsch's findings, and the importance of self-consistent theory". J.Physics: Conference Series, 329, 012018. http://iopscience.iop.org/1742-6596/329/1/012018

Also in German: www.ondwelle.com/JPhys(IR)de.pdf

Traill R.R. (2012) “A molecular basis for Piaget's 'schème' (as memory-code): Some surprising implications" -

PowerPoint presentation.

www.ondwelle.com/MolecularScheme.ppt also French: www.ondwelle.com/MolecularSchemeFr.ppt and several other languages: ...De, ..Es, ..It, ..Th, ..Ba
Traill R.R. (2015 Dec.). Notes on Reductionism and related matters. Ondwelle: Melbourne. https://www.ondwelle.com/OSM07.pdf

Traill R.R. (2019 June). "Mechanisms of Human intelligence - From RNA and Synapse to Broadband". PsyArXiv. https://doi.org/10.31234/osf.io/7w63s / Or in German: www.ondwelle.com/Untermechanismen.pdf

Traill R.R. (2022 June 4). „Kodierung für das Gehirn: RNA, ihre Photonen, und Piagetian höhere Intelligenz durch Aktion" Ondwelle: Melbourne. www.ondwelle.com/KodierungGehirn.pdf

[German version of this present paper viz. https://doi.org/10.31234/osf.io/vuhbm ]

Trettenbrein P.C. (2016) "The demise of the synapse as the locus of memory: a looming paradigm shift?"

Frontiers in Systems Neuroscience, 10: 88 https://doi.org/10.3389/fnsys.2016.00088

Umu S.U., H.Langseth, C.Bucher-Johannessen, B.Fromm, A.Keller, E.Meese, M.Lauritzen, M.Leithaug, R,Lyle \& T.B.Rounge (2018). "A comprehensive profile of circulating RNAs in human serum” RNA Biology, 15(2), 242-250. https://doi.org/10.1080/15476286.2017.1403003

Vale Ron (2015-10) Molecular motor proteins (1\&2), YouTube/iBiology/UCSF, Howard Hughes Medical Institute. — ibiology.org

Weiler N., (2018 Mar). "Birth of new neurons in the human hippocampus ends in childhood: - Adult 'neurogenesis,' observed in other species, appears not to occur in humans." Science Daily. University of California, San Francisco.

Whewell W. (1847/1840) Philosophy of the Inductive Sciences founded upon their history. London: J.W.Parker https://archive.org/stream/philosinductsci01wewrich

Yuan Sh. et 11 al (2018 Apr 6) "Cryo-EM structure of a herpesvirus capsid at $3.1 \AA$ [resolution]” Science 360(6384) (p48) https://doi.org/10.1126/science.aao7283

Zangari A., D.Micheli, R.Galeazzi \& A.Tozzi (2018) "Node of Ranvier as an array of bio-nanoantennas for infrared communication in nerve tissue" Nature: Scientific Reports, 8 , 539. https://doi.org/10.1038/s41598-017-18866-x

Zangari A., D.Micheli, R.Galeazzi \& A.Tozzi, V.Balzano, G.Bellavia \& M.E.Caristo (2021) "Photons detected in the active nerve by photographic technique" Nature: Scientific Reports, 11, 3022. https://doi.org/10.1038/s41598-02182622-5

Zeltins A. (2013) "Construction and Characterization of VirusLike Particles: A Review. Mol. Biotchnol. 53, 92-107. https://doi.org/10.1007/s12033-012-9598-4

Zolotarev V.M., B.A.Mikhailov, L.I.Alperovich, S.I.Popov (1969 Nov.). "Dispersion and absorption of liquid water in the infrared and radio regions of the spectrum". Optics and Spectroscopy. 27, 430-432. Bibcode 1969OptSp..27..430Z 